\title{
Transcriptome analysis of chrysanthemum (Dendranthema grandiflorum) in response to low temperature stress
}

Ke Wang, Zhen-yu Bai, Qian-yu Liang, Qing-lin Liu*, Lei Zhang, Yuan-zhi Pan, Guang-li Liu, Bei-bei Jiang, Fan Zhang and Yin Jia

\begin{abstract}
Background: Chrysanthemum is one kind of ornamental plant well-known and widely used in the world. However, its quality and production were severely affected by low temperature conditions in winter and early spring periods. Therefore, we used the RNA-Seq platform to perform a de novo transcriptome assembly to analyze chrysanthemum (Dendranthema grandiflorum) transcription response to low temperature.

Results: Using Illumina sequencing technology, a total of 86,444,237 high-quality clean reads and 93,837 unigenes were generated from four libraries: T01, controls; T02, $4{ }^{\circ} \mathrm{C}$ cold acclimation (CA) for $24 \mathrm{~h}$; T03, $-4{ }^{\circ} \mathrm{C}$ freezing treatments for $4 \mathrm{~h}$ with prior CA; and T04, $-4^{\circ} \mathrm{C}$ freezing treatments for $4 \mathrm{~h}$ without prior CA. In total, 7583 differentially expressed genes (DEGs) of 36,462 annotated unigenes were identified. We performed GO and KEGG pathway enrichment analyses, and excavated a group of important cold-responsive genes related to low temperature sensing and signal transduction, membrane lipid stability, reactive oxygen species (ROS) scavenging and osmoregulation. These genes encode many key proteins in plant biological processes, such as protein kinases, transcription factors, fatty acid desaturase, lipid-transfer proteins, antifreeze proteins, antioxidase and soluble sugars synthetases. We also verified expression levels of 10 DEGs using quantitative real-time polymerase chain reaction (qRT-PCR). In addition, we performed the determination of physiological indicators of chrysanthemum treated at low temperature, and the results were basically consistent with molecular sequencing results.
\end{abstract}

Conclusion: In summary, our study presents a genome-wide transcript profile of Dendranthema grandiflorum var. jinba and provides insights into the molecular mechanisms of D. grandiflorum in response to low temperature. These data contributes to our deeper relevant researches on cold tolerance and further exploring new candidate genes for chilling-tolerance and freezing-tolerance chrysanthemum molecular breeding.

Keywords: Dendranthema grandiflorum, Low temperature stress, Cold acclimation, Transciptome sequence, Differentially expressed genes

\section{Background}

Low temperature is a common environmental stress factor, which seriously affects plant growth and becomes an important factors limiting plant distribution. Plants will make a series of physiological and biochemical changes as defense systems in response to chilling $\left(0-15^{\circ} \mathrm{C}\right)$ and freezing $\left(<0 \quad{ }^{\circ} \mathrm{C}\right)$ injury [1]. These cold resistance

\footnotetext{
*Correspondence: qinglinliu@126.com

Department of Ornamental Horticulture, Sichuan Agricultural University, 211 Huimin Road, Wenjiang District, Chengdu, Sichuan 611130, People's Republic of China
}

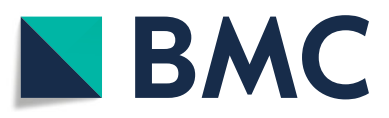

(c) The Author(s). 2018 Open Access This article is distributed under the terms of the Creative Commons Attribution 4.0 International License (http://creativecommons.org/licenses/by/4.0/), which permits unrestricted use, distribution, and reproduction in any medium, provided you give appropriate credit to the original author(s) and the source, provide a link to the Creative Commons license, and indicate if changes were made. The Creative Commons Public Domain Dedication waiver (http://creativecommons.org/publicdomain/zero/1.0/) applies to the data made available in this article, unless otherwise stated. mechanisms involve biofilm system, osmotic regulators, protective enzyme systems, and fatty acids. For many temperate plant species, exposed to chilling temperature for a period of time could increase their tolerance to subsequent freezing conditions, and this process is called 'cold acclimation (CA)' [2]. Cold acclimation can regulate many cold-responsive genes differentially expressed, induce the establishment of cold resistance mechanism, and finally improve the adaptability of plants to low temperature [3]. 
Dendranthema grandiflorum var. jinba is one of the best-selling cut chrysanthemum varieties in China. In order to realize the annual production and supply of cut chrysanthemum, in most areas of China, factories need to use the facilities for heating in winter, which greatly increases the cost of production. Thus, understanding the mechanism of chilling and freezing stress responses and improving the cold tolerance of chrysanthemum by gene transfer are of great importance.

Chrysanthemum has large genomes and lacks genomic information on the basis of cold tolerance. With the development of next-generation sequencing (NGS) technology, large scale transcriptome data has become availavle in various species [4]. In recent years, Illumina RNA-Seq technology has been successfully applied to many plant species, such as Beta vulgaris [5], Spartina pectinata [6], Camellia sinensis [7], Lilium lancifolium [8], and Camellia japonica [9], for its high accuracy and sensitivity of gene discovery.

In our study, based on Illumina NGS technology, a fully characterized chrysanthemum transcriptome was represented. Physiological experiments and molecular sequencing analysis combined to explore the cold mechanism of chrysanthemum under chilling and freezing stresses. Moreover, we compare and analyze the physiological and molecular aspects of chrysanthemum with and without cold acclimation to explore the effect of acclimation on chrysanthemum. Lots of cold-induced genes were identified, and some of them were of great importance in coldtolerance chrysanthemum molecular breeding.

\section{Methods}

\section{Plant materials and low temperature treatments}

Dendranthema grandiflorum var. jinba was used in this study. The buds raised from tissue-cultured seedlings were grown on MS medium $\left(16 \mathrm{~h}\right.$ photoperiod, $25^{\circ} \mathrm{C} / 22{ }^{\circ} \mathrm{C}$ day/ night temperature) for twenty days. Then twenty-day old chrysanthemum seedlings were transferred to pots filled with a 1:1 mixture of peat and perlite, and acclimated for three days at normal condition. Then the four groups of seedlings were respectively subjected to following treatments: (T01) normal condition as control, (T02) $4{ }^{\circ} \mathrm{C}$ for $24 \mathrm{~h}$, (T03) $4{ }^{\circ} \mathrm{C}$ for $24 \mathrm{~h}$, followed by $-4{ }^{\circ} \mathrm{C}$ for $4 \mathrm{~h}$, (T04) $-4{ }^{\circ} \mathrm{C}$ for $4 \mathrm{~h}$. Each treatment collected a mixture of three biologically replicated leaves, then samples rapidly frozen with liquid nitrogen and stored at $-80{ }^{\circ} \mathrm{C}$. There were four samples in total used for RNA-Seq and differential expression analyses.

\section{RNA preparation}

Total RNA was extracted according to manufacturer's instructions. $1 \%$ agarose gels was used for the monitoring of RNA degradation and contamination; the NanoPhotometer ${ }^{\circ}$ spectrophotometer (IMPLEN, CA, USA) was used for check of RNA purity; Qubit ${ }^{\circ}$ RNA Assay Kit was used for measurement of RNA concentration; and the RNA Nano 6000 Assay Kit of the Agilent Bioanalyzer 2100 system (Agilent Technologies, CA, USA) was used for assessing of RNA integrity.

\section{Library preparation for transcriptome sequencing}

A total amount of $3 \mu \mathrm{g}$ RNA per sample was used as input material for the RNA sample preparations. Sequencing libraries were generated using NEBNext ${ }^{\circ} \mathrm{Ultra}^{\mathrm{m}}{ }^{\mathrm{mt}}$ RNA Library Prep Kit for Illumina (NEB, USA) according to manufacturer's recommendations. Briefly, mRNA was purified from total RNA by magnetic beads and cut randomly into short fragments by fragmentation buffer. First strand cDNA was synthesized by random hexamer primer and M-MuLV Reverse Transcriptase (RNase H-), using mRNA as a template. Second strand cDNA synthesis was subsequently performed using DNA Polymerase I and RNase $\mathrm{H}$. The cDNA fragments of 150 200 bp in length were selected by AMPure XP beads, after end-repair and single nucleotide A (adenine) addition. Then, the cDNA library was obtained by PCR enrichment. At last, PCR products were purified and library quality was assessed on the Agilent Bioanalyzer 2100 system. The library preparations were sequenced on an Illumina Hiseq 4000 platform and paired-end reads were generated.

\section{Transcriptome assembly and gene functional annotation}

The clean data were obtained by removing reads containing adapter and low quality reads from raw data. Transcriptome assembly was performed using Trinity [10] based on clean data with high quality. The sequences of unigenes were compared with $\mathrm{Nr}$ (NCBI non-redundant), Pfam (Protein family), Swiss-Prot (a manually annotated and reviewed protein sequence database), GO (Gene Ontology), COG (Cluster of orthologous groups), KOG (euKaryotic Orthologous Groups) and eggNOG (evolutionary genealogy of genes: Nonsupervised Orthologous Groups) databases by BLAST, and the KEGG (Kyoto Encyclopedia of Genes and Genomes) Orthology results were obtained by comparing with KEGG using KOBAS2.0 [11]. After predicting the amino acid sequence of unigenes, we use HMMER [12] to compare them with Pfam database to get the annotation information of unigenes.

\section{Differential expression analysis}

EdgeR program package was used for adjusting read counts of each sequenced library, and DEGseq (2010) R package was used for differential expression analysis of two samples. $P$ value was adjusted using $q$ value [13]. In this study, q value $<0.01$ and $\mid \log 2$ (fold change) $\mid>1$ were set as the threshold for significantly differential expression. 
Validation of RNA-Seq data by qRT-PCR

Expression of Ten DEGs in chrysanthemum was analyzed by qRT-PCR with three replicates to verify the RNA-Seq data. The qRT-PCR was performed using the SsoFast EvaGreen supermix (Bio-Rad, Hercules, CA, USA) and Bio-Rad CFX96 $6^{\text {tu }}$ detection system. A final $10 \mu \mathrm{L}$ qRTPCR reaction mixture contained $5 \mathrm{uL}$ SsoFast EvaGreen supermix, $1 \mathrm{uL}$ diluted cDNA sample, and $150 \mathrm{nM}$ primers. Relative expression levels were calculated by the $2^{-\Delta \Delta C T}$ method, and the Elongation Factor $1 \alpha(E F 1 \alpha)$ gene (Forward primer: TTTTGGTATCTGGTCCTGGAG, Reverse primer: CCATTCAAGCGACAGACTCA) was used as a reference for quantitative expression analysis. The primers used in qRT-PCR are listed in Table 1.

\section{Determination of physiological indexes of} chrysanthemum under low temperatures

Leaves of seedlings were used for determinations. Accumulation of $\mathrm{H}_{2} \mathrm{O}_{2}$ and $\mathrm{O}_{2}{ }^{-}$was detected by histochemical staining, referring to Wang et al. (2017) [14]. Relative electrolyte conductivity (EC) was also measured following Wang et al. (2017) [14]. Peroxidase (POD) and catalase (CAT) activities were respectively measured following Ranieri et al. (2000) [15] and Zhang et al. (2011) [16]. Proline and soluble sugar contents were determinated following Irigoyen et al. (1992) [17] and Wang et al. (2013) [18]. Each determinations included three biological and technical replicates.

\section{Results}

\section{Transcriptome sequencing and assembly}

To comprehensively investigate the transcriptome and gene expression profiles of $D$. grandiflorum under normal and low temperature stress, four cDNA sample from leaves of chrysanthemum seedlings were prepared and sequenced using Illumina HiSeq 4000 platform. An overview of the RNA-Seq reads derived from the four libraries was presented in Table 2. After the low-quality reads were removed, $25.69 \mathrm{~Gb}$ clean reads were obtained with an average of $6.42 \mathrm{~Gb}$ ( 21.5 million) reads for each sample, and the percentage of Q30 base in each sample was not less than 96.33\% (Additional file 1: Figure S1).

With the Trinity program [10], a total of 199,754 transcripts were obtained from the clean reads with an N50 length of $1321 \mathrm{bp}$ and a mean length of $878.8 \mathrm{bp}$. Among them, 93,837 unigenes were generated with an average length of $719.19 \mathrm{bp}$. The length distributions of transcripts and unigenes are given in Table 3. The clean data of each sample was compared with the transcript or unigene library. The proportion of mapped reads per library ranged from $71.71 \%$ to $73.77 \%$, and unique mapped reads ranged from $47.49 \%$ to $51.43 \%$ (Table 2 ).
Table 1 Primers of qRT-PCR for validation of the selected DEGs

\begin{tabular}{|c|c|c|}
\hline Gene Name & Description & Primers \\
\hline \multirow[t]{2}{*}{$\overline{M E K K 1}$} & \multirow{2}{*}{$\begin{array}{l}\text { Mitogen-activated } \\
\text { protein kinase } \\
\text { kinase kinase }\end{array}$} & F:CAATTCGCGGAACACCAATG \\
\hline & & R:TTGAAACCGGGTCACTAACG \\
\hline \multirow[t]{2}{*}{ MYB-like } & \multirow{2}{*}{$\begin{array}{l}\text { Myb-like DNA-binding } \\
\text { domain }\end{array}$} & F:TGACCCTGATCCTGTGTITG \\
\hline & & R:GTCTACCTCTCCCAATTCATCTG \\
\hline \multirow[t]{2}{*}{ NAC90 } & \multirow{2}{*}{$\begin{array}{l}\text { NAC domain- } \\
\text { containing protein }\end{array}$} & F:TCCCACGACAAGAGAAACAAG \\
\hline & & R:TGATCCCAATGGCTCGATTAC \\
\hline \multirow[t]{2}{*}{ FAD7 } & \multirow{2}{*}{$\begin{array}{l}\text { omega-3 fatty } \\
\text { acid desaturase }\end{array}$} & F:CTCCATTCCTITCCACGGTAC \\
\hline & & R:GTTATGGGTCCGCTTCAAATG \\
\hline \multirow[t]{2}{*}{ Hsp70 } & \multirow{2}{*}{$\begin{array}{l}\text { Heat shock } 70 \mathrm{kDa} \\
\text { protein }\end{array}$} & F:CCAGCTCCACCTTGATACATC \\
\hline & & R:GAAGATTGAGGATGCGATTGATG \\
\hline \multirow[t]{2}{*}{ LEA5 } & \multirow{2}{*}{$\begin{array}{l}\text { Late embryogenesis } \\
\text { abundant protein }\end{array}$} & F:AGAAAGTGTATCCGGAAGCG \\
\hline & & R:CGTCAACTTGGCTTGTTGG \\
\hline \multirow[t]{2}{*}{ LEA3 } & \multirow{2}{*}{$\begin{array}{l}\text { Late embryogenesis } \\
\text { abundant protein }\end{array}$} & F:GGGAAAGATAAGACAGGTGGG \\
\hline & & R:GGAGTACCCATACCCAAAGC \\
\hline \multirow[t]{2}{*}{ P5CS } & \multirow{2}{*}{$\begin{array}{l}\text { pyrroline-5-carboxylate } \\
\text { synthetase }\end{array}$} & F:TTAGCAGGTCTITGTGGGTG \\
\hline & & R:GATGGGTGTTGAGAGGTAAAGG \\
\hline \multirow[t]{2}{*}{$A B F$} & \multirow{2}{*}{$\begin{array}{l}\text { ABA responsive } \\
\text { element binding factor }\end{array}$} & F:CACCAAAGACTCCAATTCAACAG \\
\hline & & R:CAGAGGGAAGAGGAAAGTGTTG \\
\hline \multirow[t]{2}{*}{$P P 2 C$} & \multirow{2}{*}{$\begin{array}{l}\text { Protein } \\
\text { phosphatase 2C }\end{array}$} & F:TTGTCGCAGTTCTCATACTCC \\
\hline & & R:TGATACGGCTTGTGGACTTG \\
\hline
\end{tabular}

\section{Gene annotation and functional classification}

To predict and analyze the function of the unigenes, we carried out functional annotation by using BLAST against multiple databases such as Nr, Swiss-Prot, GO, COG, KOG, KEGG, eggNOG, and Pfam. Of the 93,837 unigenes, 36,462 (38.86\%) unigenes were successfully matched to homologous sequences in at least one of databases mentioned above. Among them, 10,226 (10.90\%), 19,534 (20.82\%), 12,584 (13.41\%), 20,400 (21.74\%), 24,137 (25.72\%), 23,437 (24.98\%), 33,201 (35.38\%) and 35,370 (37.69\%) unigenes were found in COG, GO, KEGG, KOG, Pfam, Swiss-Prot, eggNOG, and Nr databases, respectively. The $\mathrm{Nr}$ database produced the largest number of annotations. Compared with other species, chrysanthemum var. jinba showed the most matches to Vitis vinifera (3771), followed by Sesamum indicum (2623) and Coffea canephora (2230) (Fig. 1a).

Table 2 Overview of the sequencing and assembly

\begin{tabular}{lllllll}
\hline $\begin{array}{l}\text { Sample } \\
\text { ID }\end{array}$ & $\begin{array}{l}\text { rean } \\
\text { reads }\end{array}$ & $\begin{array}{l}\text { Clean } \\
\text { bases }\end{array}$ & Q30 & $\begin{array}{l}\text { GC } \\
\text { content }\end{array}$ & $\begin{array}{l}\text { Mapped } \\
\text { reads }\end{array}$ & $\begin{array}{l}\text { Unique } \\
\text { match }\end{array}$ \\
\hline T01 & $22,802,541$ & $6,774,398,078$ & $96.33 \%$ & $43.62 \%$ & $73.40 \%$ & $51.43 \%$ \\
T02 & $21,839,313$ & $6,501,753,240$ & $96.52 \%$ & $42.93 \%$ & $73.77 \%$ & $49.89 \%$ \\
T03 & $20,478,749$ & $6,077,198,988$ & $96.78 \%$ & $42.90 \%$ & $73.10 \%$ & $47.49 \%$ \\
T04 & $21,323,634$ & $6,339,923,198$ & $96.68 \%$ & $42.88 \%$ & $71.71 \%$ & $49.06 \%$ \\
\hline
\end{tabular}


Table 3 Length distribution of the transcripts and unigenes clustered from de novo assembly

\begin{tabular}{lll}
\hline Length range & Transcript & Unigene \\
\hline 200-300 & $40,988(20.52 \%)$ & 30,475 \\
$300-500$ & $44,661(22.36 \%)$ & 23,753 \\
$500-1000$ & $54,466(27.27 \%)$ & 19,857 \\
$1000-2000$ & $41,917(20.98 \%)$ & 13,504 \\
2000 & $17,722(8.87 \%)$ & 6248 \\
Total number & 199,754 & 93,837 \\
Total length & $175,543,436$ & $67,486,480$ \\
N50 length & 1321 & 1155 \\
Mean length & 878.8 & 719.19 \\
\hline
\end{tabular}

GO assignments system was used to classify the possible functions of chrysanthemum genes. A total of 19,534 unigenes were successfully annotated and classified into 52 functional groups of three major GO categories (Cell Component (CC), Molecular Function (MF), and Biological Processes (BP)) (Fig. 1b). The top three GO terms for classified genes were 'cell' (8319), 'cell part'(8319) and 'organelle' (6248) for cell component category; 'catalytic activity' (11,009), 'binding' (9622) and 'transporter activity' (1273) for molecular function; and 'metabolic process' $(13,917)$, 'cellular process' $(11,378)$ and 'single-organism process' (9623) for biological processes. In addition, genes involved in 'membrane,' 'response to stimulus' and 'biological regulation' were also highly represent.

In total, 20,400 unigenes were grouped into 25 functional classifications based on KOG database (Fig. 1c). Among these classification, the largest group was 'general function prediction only' (5176), followed by 'posttranslational modification, protein turnover, chaperones' (2117), 'signal transduction mechanisms' (2046), 'carbohydrate transport and metabolism' (1140), 'secondary metabolites biosynthesis, transport and catabolism' (1115), 'translation, ribosomal structure and biogenesis' (1081), and 'transcription' (1067).

\section{Analysis of potential differentially expressed genes (DEGs)} The clean reads from each sample were compared to the unigene library, and gene expression levels were estimated using RSEM (RNA-Seq by Expectation Maximization) according to the results of comparison. FPKM (fragments per kilobase of transcript per million fragments mapped) values were used to indicate the expression abundance of unigenes.

From three comparison, including CP1 (T01 vs T02), CP2 (T01 vs T03) and CP3 (T01 vs T04), a large number of DEGs were identified. The number of DEGs detected was as follows: CP1 3028 (1846 up- and 1182 downregulated), CP2 3906 (2799 and 1107) and CP3 3245
(2270 and 975) (Fig. 2b). We found that more DEGs up regulated in treatment $\mathrm{T} 03$ which underwent CA than the treatment T04 without CA. Moreover, the venn diagram was used for analyses of unique and overlapping sets of DEGs in each treatment. As shown in Fig. 2a, there were 641 genes differentially expressed in all comparisons, indicating that these genes involved in the process of plants response to both chilling and freezing stresses, which were of great value for low temperature tolerance study. We also identified 1166, 1086 and 1324 DEGs expressed only in T02, T03 and T04, respectively. Thus it can be seen that there were 1166 genes only playing roles in the process of CA, not working in freezing period, and 1324 genes involved in response to rapid freezing. Of total 6557 DEGs, 4378 genes were successfully annotated with eight databases. The number of annotated DEGs in each treatment is shown in Table 4.

\section{KEGG pathway analysis for DEGs}

KEGG annotation was used for DEGs from the above comparisons. In the CP1, 493 DEGs were assigned to the KEGG database involved 108 pathways; for CP2, 519 DEGs were assigned to 113 pathways; and for CP3, 386 DEGs assigned to 105 pathways. The most reliable top ten significantly enriched pathways of DEGs under low temperature treatments were represented as Table 5.

Integrate these three comparisons, the major pathways involved in the cold response mechanism were 'Starch and sucrose metabolism,' 'Galactose metabolism, 'Glycerophospholipid metabolism,' 'Biosynthesis of unsaturated fatty acids', 'Plant hormone signal transduction' and 'Plantpathogen interaction' (Additional file 1: Figure S2). As shown in Table 6, for first four biological metabolism and synthesis pathways, the number of DEGs in CP1 was more than CP2 or CP3; but for last two signal transduction related pathways, DEGs number of CP1 was less than CP2 or CP3.

\section{Protein kinase (PK) and transcription factors (TFs) responding to low temperature}

A total of 96, 131, and 129 DEGs encoding protein kinases belonging to 23 major families were found in CP1, CP2 and CP3 treatments, respectively. Among them, 51 (14 up- and 37 down-regulated), 71 (50 and 21) and 80 (71 and 9) receptor-like kinases (RLKs) were identified. And there were 4 (2 up- and 2 downregulated), 8 (7 and 1$)$ and 10 (10 and 0$)$ genes of $C P 1$, CP2 and CP3 involved in the mitogen-activated protein kinase (MAPK) cascade. We found 3, 12 and 9 DEGs of calcium-dependent protein kinase (CDPK) family and 7, 5 and 4 DEGs of CBL-interacting protein kinase (CIPK) family were all up regulated in CP1, CP2 and CP3. Moreover, we identified 13, 12 and 11 protein phosphatase (PP) differentially expressed in three treatments. The 

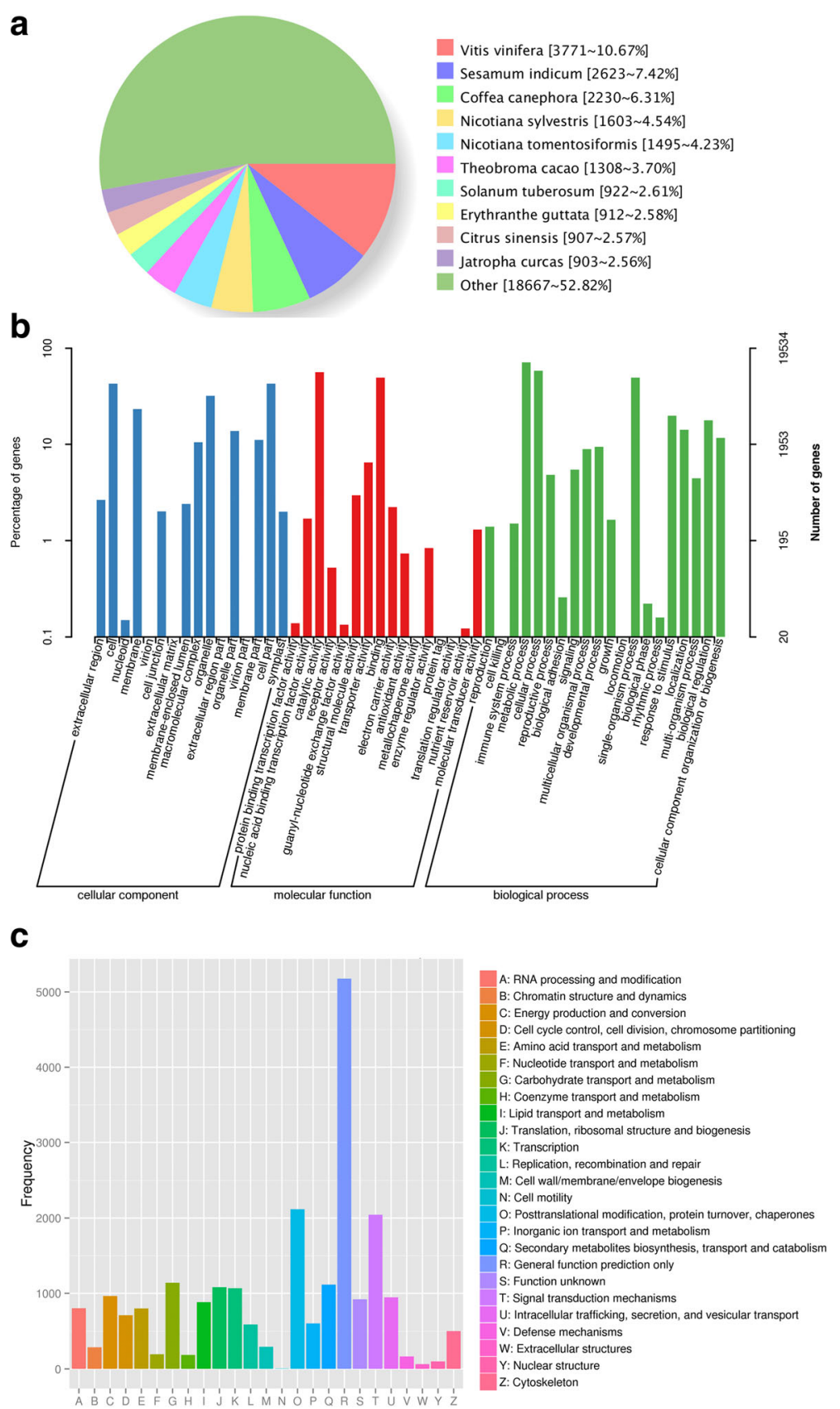

Fig. 1 Functional annotation of assembled transcriptome. a Similarity of D. grandiflorum var. Jinba sequences with those of other species. $\mathbf{b}$ GO classification of the annotated unigenes. c KOG function classification of consensus sequence

details of these PK and PP genes are shown in Additional file 2: Table S1. These results indicated that protein phosphorylation may be induced by low temperature in chrysanthemum. In addition, it was interesting that there were more up-regulated $\mathrm{PK}$ in $\mathrm{CP} 2$ and CP3 than CP1 (Fig. 3a).

In this study, totally 123 (84 up- and 39 downregulated), 190 (157 and 33) and 193 (172 and 21) transcription factor (TF) genes were identified in CP1, CP2 and CP3. Obviously, the number of up- regulated expressed transcription TFs in CP2 and CP3 was greater than that of CP1 (Fig. 3b). A large number of TF families were involved in low temperature response. Generally, the major TF families were AP2/ERF, WRKY, bHLH, MYB, MYB-related, and NAC. In treatment CP1, the AP2/ERF family was the largest group (18\%), followed by the bHLH family (8\%) and the GARP-G2-like family (6\%); for CP2, the top three family were AP2/ERF (17\%), 

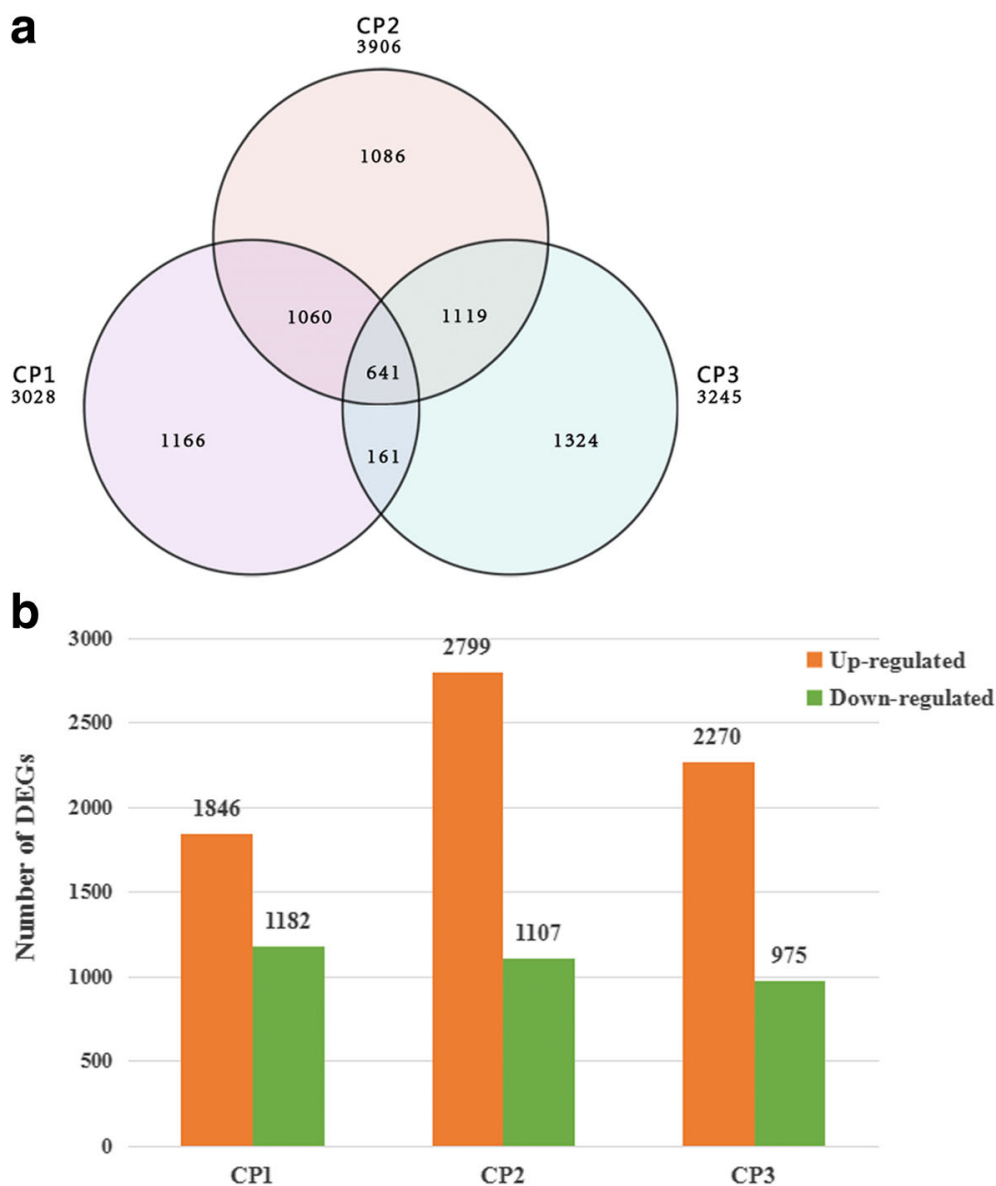

Fig. 2 Venn diagram and histogram of DEGs during low temperature stresses. a Venn diagram showing DEGs expressed at each of the three low temperature treatments. $\mathbf{b}$ The numbers of DEGs identified in comparisons between pairs of libraries

WRKY (12\%) and MYB (7\%); and for CP3, the top three were AP2/ERF (20\%), WRKY (10\%), MYB (10\%) (Additional file 1: Figure S3). Of AP2/ERF genes, 17, 29 and 33 were up-regulated in $\mathrm{CP} 1, \mathrm{CP} 2$ and $\mathrm{CP} 3$, respectively. And the members of WRKY and MYB families were more active in freezing condition rather than in chilling condition.

Table 4 DEGs annotation of D. grandiflorum var. Jinba

\begin{tabular}{llll}
\hline & CP1 & CP2 & CP3 \\
\hline Total annotated & 2280 & 2530 & 2166 \\
COG & 813 & 796 & 562 \\
GO & 1335 & 1390 & 1101 \\
KEGG & 827 & 832 & 596 \\
KOG & 1311 & 1332 & 990 \\
Pfam & 1825 & 1966 & 1627 \\
Swiss-Prot & 1654 & 1813 & 1534 \\
eggNOG & 2181 & 2400 & 2040 \\
Nr & 2257 & 2497 & 2140 \\
\hline
\end{tabular}

Gene related to the membrane system and osmoregulation

The increase of membrane lipids unsaturation level can increase the fluidity of membrane, accordingly improving the cold resistance of plants [19]. In our study, we identified 12 lipid-transfer proteins (LTPs) and 7 fatty acid desaturase (FADs) genes. Among them, 5 LTPs and 3 FADs were up-regulated in CP1, 7 LTPs and 5 FADs up-regulalted in CP2, and only 4 LTPs and 1 FADs were up-regulated in CP3. The details of genes related to the biofilm system are shown in Table 7.

According to the pathway enrichment analysis, 'starch and sucrose metabolism' (ko00500), 'galactose metabolism' (ko00052), 'arginine and proline metabolism' (ko00330) involved plenty of genes that regulating and relieving the osmotic stress caused by cold-evoked dehydration. In the treatment CP1, 7 starch-degrading genes, 4 cellulose-degrading genes, 3 sucrose-phosphate synthase (SPS) genes, 2 trehalose phosphate synthase (TPS) genes, 3 trehalose phosphatase (TPP) genes, 3 galactinol synthase genes, 4 
Table 5 The most reliable top ten significantly enriched pathways of DEGs under low temperature treatments

\begin{tabular}{|c|c|c|c|c|c|}
\hline & Pathway ID & Pathway & DEGs in pathway & All genes in pathway & $P$-value \\
\hline \multirow[t]{10}{*}{ CP1 } & ko03008 & Ribosome biogenesis in eukaryotes & 47 & 137 & $5.59 \mathrm{E}-13$ \\
\hline & ko00196 & Photosynthesis - antenna proteins & 20 & 64 & 3.19E-09 \\
\hline & ko00940 & Phenylpropanoid biosynthesis & 38 & 233 & 2.53E-07 \\
\hline & ko00500 & Starch and sucrose metabolism & 42 & 301 & 4.29E-06 \\
\hline & ko00052 & Galactose metabolism & 17 & 104 & 0.0005392 \\
\hline & ko00400 & Phenylalanine, tyrosine and tryptophan biosynthesis & 13 & 78 & 0.0019789 \\
\hline & ko00906 & Carotenoid biosynthesis & 8 & 38 & 0.0032878 \\
\hline & ko00130 & Ubiquinone and other terpenoid-quinone biosynthesis & 10 & 66 & 0.0123906 \\
\hline & ko00603 & Glycosphingolipid biosynthesis - globo series & 3 & 8 & 0.0132652 \\
\hline & ko00360 & Phenylalanine metabolism & 17 & 143 & 0.0156871 \\
\hline \multirow[t]{10}{*}{$\mathrm{CP} 2$} & ko03008 & Ribosome biogenesis in eukaryotes & 31 & 137 & 4.55E-09 \\
\hline & ko00196 & Photosynthesis - antenna proteins & 20 & 64 & 7.76E-09 \\
\hline & ko04626 & Plant-pathogen interaction & 45 & 272 & $5.72 \mathrm{E}-08$ \\
\hline & ko00940 & Phenylpropanoid biosynthesis & 29 & 233 & 0.0020767 \\
\hline & ko00564 & Glycerophospholipid metabolism & 20 & 149 & 0.0042047 \\
\hline & ko00360 & Phenylalanine metabolism & 19 & 143 & 0.0058143 \\
\hline & ko00052 & Galactose metabolism & 15 & 104 & 0.0064176 \\
\hline & ko00500 & Starch and sucrose metabolism & 33 & 301 & 0.0079662 \\
\hline & ko04075 & Plant hormone signal transduction & 38 & 360 & 0.0084879 \\
\hline & ko00740 & Riboflavin metabolism & 3 & 8 & 0.0152681 \\
\hline \multirow[t]{10}{*}{ CP3 } & ko00196 & Photosynthesis - antenna proteins & 28 & 64 & 0 \\
\hline & ko04626 & Plant-pathogen interaction & 33 & 272 & 5.61E-06 \\
\hline & ko04075 & Plant hormone signal transduction & 39 & 360 & $1.24 \mathrm{E}-05$ \\
\hline & ko00860 & Porphyrin and chlorophyll metabolism & 14 & 77 & 4.17E-05 \\
\hline & ko04712 & Circadian rhythm - plant & 11 & 55 & 0.0001138 \\
\hline & ko00906 & Carotenoid biosynthesis & 8 & 38 & 0.0006843 \\
\hline & ko00195 & Photosynthesis & 15 & 114 & 0.0009170 \\
\hline & ko00740 & Riboflavin metabolism & 3 & 8 & 0.0067278 \\
\hline & ko00591 & Linoleic acid metabolism & 6 & 36 & 0.0106150 \\
\hline & ko00564 & Glycerophospholipid metabolism & 14 & 149 & 0.0256548 \\
\hline
\end{tabular}

raffinose synthase gene and 1 pyrroline-5-carboxylate synthetase (P5CS) gene were up-regulated; an equivalent order for CP2 were 7, 3, 3, 2, 3, 3, 4 and 1; for CP3 were 4, 1, 0, 0, 2, 1, 3 and 0 . Evidently, under freezing conditions, activities of starch and cellulose degradation and above

Table 6 DEG statistics in five major pathways

\begin{tabular}{llll}
\hline \#Pathways & CP1 & CP2 & CP3 \\
\hline Starch and sucrose metabolism & 42 & 33 & 22 \\
Galactose metabolism & 17 & 15 & 6 \\
Glycerophospholipid metabolism & 14 & 20 & 14 \\
Biosynthesis of unsaturated fatty acids & 7 & 9 & 1 \\
Plant hormone signal transduction & 29 & 38 & 39 \\
Plant-pathogen interaction & 19 & 45 & 33 \\
\hline
\end{tabular}

soluble sugars syntheses were decreased in chrysanthemum without cold acclimation (T04). The details of genes related to osmotic regulation system are shown in Table 8.

Moreover, we found a group of cold-related proteins, including cold-regulated (COR), cold shock and heat shock proteins (HSPs), which were invovled in the low temperature stress response process. Among them, HSPs accounted for a large proportion. And we also identified some anti-freezing proteins (AFPs) [7], such as beta-1,3glucanase proteins (GLPs), thaumatin-like proteins (TLPs) , polygalacturonase-inhibiting proteins (PGIPs) and lateembryogenesis-abundant proteins (LEAs). In total, there were 14, 17 and 13 AFPs-related genes up-regulated in $\mathrm{CP} 1, \mathrm{CP} 2$ and $\mathrm{CP} 3$, respectively. These genes are shown as Table 9. 

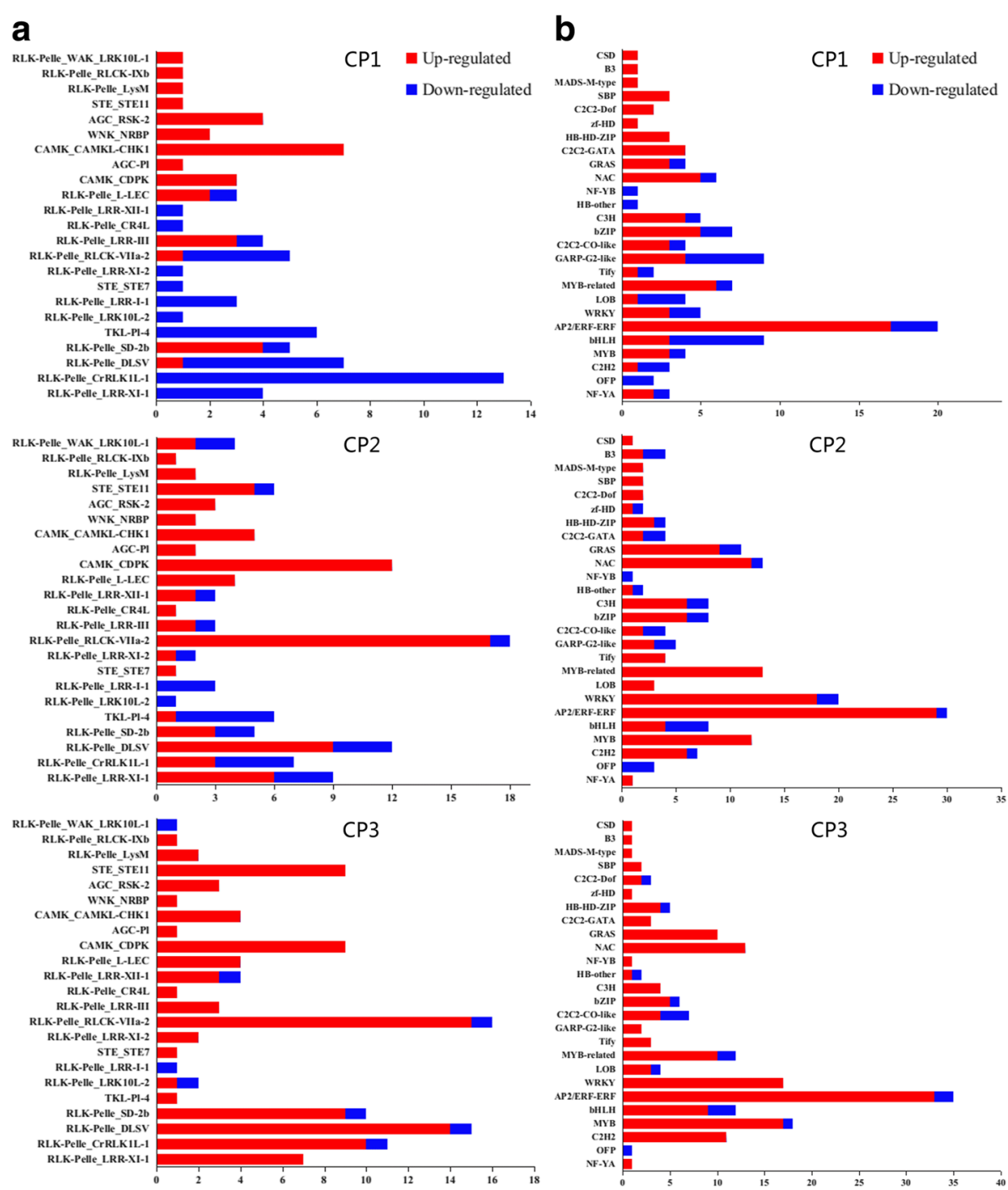

Fig. 3 Differentially expressed protein kinases $\mathbf{a}$ and transcription factors $\mathbf{b}$ responsive to low temperature. Within each bar, number of up- and down-regulated genes is shown in red and blue, respectively

Plant hormone signal transduction pathway

A total of 68 DEGs were invovled in several plant hormone signal transduction pathways, such as auxin, cytokinin (CK), gibberellin (GA), abscisic acid (ABA), ethylelne (ET), brassinosteroid (BR), jasmonic acid (JA) and salicylic acid (SA) in our study. Among them, auxin, ABA, ET and JA pathways were predominatly induced. In the auxin signaling pathway, there were 9,10 and 9 genes up-regulated in T02, T03 and T04; in the CK pathway, the number of up-regulated genes in three treatments was 4,3 and 2; in the ET pathway, the number was 2,2 and 7 ; and in the JA pathway, the number was 1,5 and 7. In ABA signaling pathway, totally $4 \mathrm{ABA}$ receptor genes, $1 \mathrm{ABA}$ responsive element binding factor $(\mathrm{ABF})$ gene, 4 serine/threonine-protein kinase SRK2 (SnRK2) genes, and 6 protein phosphatase 2C (PP2C) genes were differentially expressed during low temperature conditions. Unexpectedly, under the chilling condition, there was no gene differentially expressed in the SA signaling pathway, while one gene up-regulated under freezing conditions. The above results suggested that plant hormone played important roles in response to low temperature stress in chrysanthemum.

\section{Verification of DEGs using qRT-PCR}

To further verify the expression levels of genes obtained from Illumina RNA-Seq platform, we have selected ten genes induced by low temperature to perform qRT-PCR, including genes encoding protein 
Table 7 Gene related to the biofilm system in response to low temperature

\begin{tabular}{|c|c|c|c|c|c|c|c|c|}
\hline & Gene ID & CP1 $\log 2 F C$ & $\mathrm{CP} 1$ regulated & $\mathrm{CP} 2 \log 2 \mathrm{FC}$ & $\mathrm{CP} 2$ regulated & $\mathrm{CP} 3 \log 2 \mathrm{FC}$ & $\mathrm{CP} 3$ regulated & Gene description \\
\hline \multirow[t]{12}{*}{ LTPS } & c98772.graph_c0 & 2.06 & up & 2.26 & up & 0.38 & normal & Non-specific lipid transfer protein \\
\hline & c94507.graph_c0 & 0.43 & normal & -0.12 & normal & 1.13 & up & Non-specific lipid transfer protein \\
\hline & C90293.graph_c0 & 4.24 & up & 4.30 & up & 1.47 & normal & $\begin{array}{l}\text { Non-specific lipid-transfer } \\
\text { protein-like protein }\end{array}$ \\
\hline & c86130.graph_c0 & 4.39 & up & 4.66 & up & 1.53 & normal & Lipid transfer-like protein \\
\hline & c96305.graph_c0 & 1.50 & normal & 2.41 & up & 1.28 & normal & $\begin{array}{l}\text { Non-specific lipid-transfer } \\
\text { protein-like protein }\end{array}$ \\
\hline & c93927.graph_c1 & 3.17 & normal & 3.48 & up & - & - & $\begin{array}{l}\text { Probable non-specific lipid- } \\
\text { transfer protein-like protein }\end{array}$ \\
\hline & C111292.graph_c1 & 3.44 & up & 3.97 & up & 1.36 & up & $\begin{array}{l}\text { Non-specific lipid-transfer } \\
\text { protein-like protein }\end{array}$ \\
\hline & c95472.graph_c0 & 0.93 & normal & 1.38 & normal & 2.16 & up & Non-specific lipid-transfer protein \\
\hline & c45235.graph_c0 & 3.55 & up & 2.77 & normal & 3.83 & up & Putative lipid-transfer protein \\
\hline & c91182.graph_c0 & 0.78 & normal & 0.86 & normal & -1.50 & down & Lipid transfer protein EARLI 1 \\
\hline & c92863.graph_c0 & 2.98 & normal & 3.81 & up & - & - & $\begin{array}{l}\text { Non-specific lipid-transfer } \\
\text { protein-like protein }\end{array}$ \\
\hline & C95124.graph_c0 & -0.95 & normal & -1.41 & normal & -3.08 & down & Lipid transfer protein EARLI 1 \\
\hline \multirow[t]{7}{*}{ FADs } & c103089.graph_c1 & 3.38 & up & 2.95 & up & -0.09 & normal & Omega-3 fatty acid desaturase \\
\hline & c98666.graph_c0 & 3.35 & up & 2.63 & up & 0.11 & normal & Omega-3 fatty acid desaturase \\
\hline & c86611.graph_c0 & 1.84 & up & 1.59 & normal & 0.21 & normal & Omega-3 fatty acid desaturase \\
\hline & c87665.graph_c0 & 1.21 & normal & 2.50 & up & 0.56 & normal & Omega- 6 fatty acid desaturase \\
\hline & c87665.graph_c1 & 1.02 & normal & 2.44 & up & 0.88 & normal & Omega- 6 fatty acid desaturase \\
\hline & c86525.graph_c0 & 0.64 & normal & 2.02 & up & -0.58 & normal & Omega- 6 fatty acid desaturase \\
\hline & c106808.graph_c0 & -0.07 & normal & 0.82 & normal & 1.26 & up & Omega- 6 fatty acid desaturase \\
\hline \multirow[t]{6}{*}{ PLDs } & c105153.graph_c0 & 0.03 & normal & 0.95 & normal & 1.10 & up & Phospholipase D alpha 1 \\
\hline & c112648.graph_c0 & 3.42 & up & 3.67 & up & 1.43 & up & Phospholipase D alpha 1 \\
\hline & c115302.graph_c0 & 3.50 & up & 4.51 & up & 0.49 & normal & Phospholipase D p1 \\
\hline & c98821.graph_c0 & 2.89 & up & 3.39 & up & 0.97 & normal & Phospholipase D alpha 1 \\
\hline & c114556.graph_c0 & -2.12 & down & -3.02 & down & -0.19 & normal & phospholipase D Z-like \\
\hline & c113287.graph_c0 & -0.20 & normal & 2.22 & up & 0.71 & normal & Phospholipase D beta 1 \\
\hline \multirow[t]{3}{*}{ SPLA2 } & c116204.graph_c1 & -0.83 & normal & 1.78 & normal & 1.59 & up & Triacylglycerol lipase SDP1 \\
\hline & c96544.graph_c0 & 1.75 & up & 0.35 & normal & 2.09 & up & Phospholipase A2-alpha \\
\hline & c105515.graph_c0 & 2.17 & up & 1.65 & normal & 0.94 & normal & Patatin-like phospholipase \\
\hline \multirow[t]{9}{*}{ POD } & c96977.graph_c0 & - & - & 3.80 & up & 2.84 & up & Peroxidase N1 \\
\hline & c103682.graph_c0 & 4.29 & up & 3.85 & up & 4.27 & up & Peroxidase 17 \\
\hline & c106645.graph_c0 & 3.36 & up & 3.94 & up & 1.70 & normal & Cationic peroxidase 1 \\
\hline & c113544.graph_c0 & -2.75 & down & -0.11 & normal & -0.22 & normal & Peroxidase N1 \\
\hline & c100631.graph_c0 & - & - & 3.97 & up & 4.86 & up & Lignin-forming anionic peroxidase \\
\hline & c114296.graph_c0 & -0.51 & normal & -1.66 & normal & -2.82 & down & Peroxidase 64 \\
\hline & c90653.graph_c0 & -3.06 & down & -0.21 & normal & 0.24 & normal & Peroxidase (Precursor) \\
\hline & c98404.graph_c0 & 0.17 & normal & 0.26 & normal & -2.07 & down & $\begin{array}{l}\text { Lignin-forming anionic } \\
\text { peroxidase (Precursor) }\end{array}$ \\
\hline & c99288.graph_c0 & -2.62 & down & -2.34 & down & -0.69 & normal & Peroxidase 12 \\
\hline
\end{tabular}

kinases, transcription factors, fatty acid desaturase, heat shock protein, late-embryogenesis-abundant protein, pyrroline-5-carboxylate synthetase, ABA-responsive element binding factor and polygalacturonase-inhibiting protein. The results of experiment showed a strong correlation with the RNA-Seq data (Fig. 4). 
Table 8 Gene related to osmotic regulation system in response to low temperature

\begin{tabular}{|c|c|c|c|c|c|c|c|c|}
\hline & Gene ID & CP1 log2FC & CP1 regulated & CP2 log2FC & CP2 regulated & CP3 log2FC & CP3 regulated & Gene description \\
\hline \multirow{8}{*}{$\begin{array}{l}\text { Starch-degrading } \\
\text { genes }\end{array}$} & c106047.graph_c0 & 1.82 & normal & 2.10 & up & 0.57 & normal & Beta-amylase \\
\hline & c111660.graph_c0 & 4.57 & up & 4.51 & up & 4.83 & up & Beta-amylase \\
\hline & c98302.graph_c0 & 3.25 & up & 3.61 & up & 1.87 & up & Beta-amylase \\
\hline & c111420.graph_c0 & 2.83 & up & 3.22 & up & 1.81 & up & Beta-amylase \\
\hline & c111420.graph_c1 & 2.83 & up & 3.22 & up & 1.58 & up & Beta-amylase \\
\hline & c102389.graph_c0 & 2.43 & up & 1.99 & up & 0.97 & normal & $\begin{array}{l}\text { Probable } \\
\text { alpha-amylase }\end{array}$ \\
\hline & c116071.graph_c0 & 2.01 & up & 1.94 & normal & -0.90 & normal & Alpha-amylase \\
\hline & c116145.graph_c0 & 1.93 & up & 2.06 & up & 0.02 & normal & Alpha-amylase \\
\hline \multirow[t]{12}{*}{$\begin{array}{l}\text { Cellulose-degrading } \\
\text { genes }\end{array}$} & c111098.graph_c0 & 2.59 & up & 2.32 & up & 1.37 & normal & $\begin{array}{l}\text { Beta glucosidase } 41 \\
\text { isoform } 3\end{array}$ \\
\hline & c91317.graph_c0 & 2.74 & up & 2.02 & normal & 0.98 & normal & $\begin{array}{l}\text { Raucaffricine-O- } \\
\text { beta-D- glucosidase }\end{array}$ \\
\hline & c108565.graph_c1 & 1.88 & up & 1.43 & normal & 0.26 & normal & $\begin{array}{l}\text { lysosomal beta } \\
\text { glucosidase-like }\end{array}$ \\
\hline & c96136.graph_c0 & 2.96 & up & 2.90 & up & 0.33 & normal & Beta-glucosidase 18 \\
\hline & c106631.graph_c0 & -2.07 & down & -1.52 & normal & 0.23 & normal & $\begin{array}{l}\text { Strictosidine-O- } \\
\text { beta-D- glucosidase }\end{array}$ \\
\hline & c104722.graph_c1 & -2.20 & down & -2.06 & normal & -0.81 & normal & $\begin{array}{l}\text { Probable beta-D- } \\
\text { xylosidase } 5\end{array}$ \\
\hline & c93973.graph_c0 & -3.35 & down & -1.34 & normal & -0.06 & normal & $\begin{array}{l}\text { lysosomal beta } \\
\text { glucosidase-like } \\
\text { isoform X1 }\end{array}$ \\
\hline & c98430.graph_c0 & -1.82 & down & -1.98 & normal & -0.44 & normal & Beta-glucosidase 18 \\
\hline & c98430.graph_c1 & -2.07 & down & -2.41 & down & -0.82 & normal & $\begin{array}{l}\text { beta-glucosidase } \\
18 \text { isoform X1 }\end{array}$ \\
\hline & c104480.graph_c0 & 0.12 & normal & 2.23 & up & 0.56 & normal & $\begin{array}{l}\text { Probable beta-D- } \\
\text { xylosidase } 5\end{array}$ \\
\hline & c112478.graph_c0 & 1.49 & normal & 1.12 & normal & 1.12 & up & Beta-glucosidase 11 \\
\hline & c114139.graph_c0 & -1.23 & normal & -1.96 & normal & -1.23 & down & Beta-glucosidase 18 \\
\hline \multirow[t]{3}{*}{ SPS } & C114821.graph_c1 & 3.09 & up & 3.44 & up & 0.34 & normal & $\begin{array}{l}\text { sucrose phosphate } \\
\text { synthase }\end{array}$ \\
\hline & c114715.graph_c0 & 2.56 & up & 2.48 & up & -0.88 & normal & $\begin{array}{l}\text { sucrose phosphate } \\
\text { synthase }\end{array}$ \\
\hline & c114821.graph_c0 & 3.67 & up & 4.00 & up & 0.92 & normal & $\begin{array}{l}\text { sucrose phosphate } \\
\text { synthase }\end{array}$ \\
\hline SS & c103323.graph_c0 & -1.84 & normal & -1.53 & normal & 1.11 & up & Sucrose synthase 3 \\
\hline \multirow[t]{5}{*}{ TPS } & c102854.graph_c0 & -4.99 & down & -2.01 & normal & -1.08 & normal & $\begin{array}{l}\text { Probable alpha, } \\
\text { alpha-trehalose- } \\
\text { phosphate synthase }\end{array}$ \\
\hline & c104136.graph_c0 & -4.61 & down & -1.25 & normal & -0.91 & normal & $\begin{array}{l}\text { Probable alpha, } \\
\text { alpha-trehalose- } \\
\text { phosphate synthase }\end{array}$ \\
\hline & c115624.graph_c0 & -2.17 & down & -0.23 & normal & -0.63 & normal & $\begin{array}{l}\text { trehalose-6- } \\
\text { phosphate synthase }\end{array}$ \\
\hline & c92114.graph_c0 & 2.38 & normal & 3.25 & up & - & - & $\begin{array}{l}\text { trehalose-7- } \\
\text { phosphate synthase }\end{array}$ \\
\hline & c112854.graph_c0 & -3.03 & down & -1.39 & normal & -1.34 & down & $\begin{array}{l}\text { Probable alpha, } \\
\text { alpha-trehalose- } \\
\text { phosphate synthase }\end{array}$ \\
\hline
\end{tabular}


Table 8 Gene related to osmotic regulation system in response to low temperature (Continued)

\begin{tabular}{|c|c|c|c|c|c|c|c|c|}
\hline & Gene ID & CP1 log2FC & CP1 regulated & $\mathrm{CP} 2 \log 2 \mathrm{FC}$ & CP2 regulated & CP3 log2FC & CP3 regulated & Gene description \\
\hline & c113270.graph_c0 & -2.41 & down & 1.08 & normal & 0.44 & normal & $\begin{array}{l}\text { Probable alpha, } \\
\text { alpha-trehalose- } \\
\text { phosphate synthase }\end{array}$ \\
\hline & c93906.graph_c0 & -4.25 & down & -2.27 & normal & -0.82 & normal & $\begin{array}{l}\text { Probable alpha, } \\
\text { alpha-trehalose- } \\
\text { phosphate synthase }\end{array}$ \\
\hline & c99330.graph_c0 & 3.86 & up & 3.89 & up & - & - & $\begin{array}{l}\text { Alpha, } \\
\text { alpha-trehalose- } \\
\text { phosphate synthase }\end{array}$ \\
\hline & c107046.graph_c1 & -1.62 & normal & -2.72 & down & -0.88 & normal & $\begin{array}{l}\text { trehalose 6- } \\
\text { phosphate synthase }\end{array}$ \\
\hline & c108202.graph_c0 & -3.46 & down & 0.56 & normal & -0.17 & normal & $\begin{array}{l}\text { Probable alpha, } \\
\text { alpha-trehalose- } \\
\text { phosphate synthase }\end{array}$ \\
\hline & c94647.graph_c0 & 2.41 & up & 1.49 & normal & - & - & $\begin{array}{l}\text { Alpha, } \\
\text { alpha-trehalose- } \\
\text { phosphate synthase }\end{array}$ \\
\hline & c86304.graph_c0 & -3.60 & down & -1.52 & normal & -0.57 & normal & $\begin{array}{l}\text { Probable alpha, } \\
\text { alpha-trehalose- } \\
\text { phosphate synthase }\end{array}$ \\
\hline \multirow[t]{3}{*}{ TPP } & c110653.graph_c0 & 3.26 & up & 5.87 & up & 5.00 & up & $\begin{array}{l}\text { trehalose-phosphate } \\
\text { phosphatase }\end{array}$ \\
\hline & c116316.graph_c0 & 1.99 & up & 2.15 & up & 1.00 & normal & $\begin{array}{l}\text { trehalose-phosphate } \\
\text { phosphatase }\end{array}$ \\
\hline & c104330.graph_c0 & 3.07 & up & 3.06 & up & 2.73 & up & $\begin{array}{l}\text { trehalose-phosphate } \\
\text { phosphatase }\end{array}$ \\
\hline \multirow{5}{*}{$\begin{array}{l}\text { Raffinose } \\
\text { synthase genes }\end{array}$} & c80434.graph_c0 & 2.58 & up & 3.34 & up & 1.41 & normal & Galactinol synthase \\
\hline & c98797.graph_c0 & 4.00 & up & 5.46 & up & 1.90 & up & Galactinol synthase \\
\hline & c81587.graph_c0 & 2.44 & up & 2.55 & up & 0.97 & normal & Galactinol synthase \\
\hline & c115834.graph_c0 & 4.05 & up & 7.49 & up & 4.99 & up & $\begin{array}{l}\text { Probable } \\
\text { galactinol-sucrose } \\
\text { galactosyltransferase }\end{array}$ \\
\hline & c115556.graph_c0 & -4.49 & down & 1.01 & normal & 1.97 & up & $\begin{array}{l}\text { Probable } \\
\text { galactinol-sucrose } \\
\text { galactosyltransferase }\end{array}$ \\
\hline galM & c98143.graph_c0 & -1.78 & down & -1.26 & normal & -0.44 & normal & Aldose 1-epimerase \\
\hline galA & c110075.graph_c0 & -2.00 & down & -2.54 & down & -0.43 & normal & Alpha-galactosidase \\
\hline P5CS & c110924.graph_c0 & 2.76 & up & 2.95 & up & 0.74 & normal & $\begin{array}{l}\text { pyrroline-5- } \\
\text { carboxylate } \\
\text { synthetase }\end{array}$ \\
\hline
\end{tabular}

\section{Analyses of phenotypic and physiological changes of chrysanthemum at different low temperatures.}

As shown in Fig. 5a, the phenotypes of chrysanthemum seedlings under chilling stress $\left(4^{\circ} \mathrm{C}\right)$ was not significantly different from those under normal conditions, but only the youngest leaves of individual seedlings appeared dying. And under freezing stress $\left(-4{ }^{\circ} \mathrm{C}\right)$, it was clear that the seedlings without prior CA (T04) were more wilted than those with CA (T03). Under low temperature, the membrane permeability of chrysanthemum leaves increased and electrolyte leakage occurred. The degree of electrolyte extravasation was higher in chrysanthemum under freezing conditions than that under the chilling condition (Fig. 5c). And the electrolyte conductivity of T03 was lower than T04, suggesting that CA could increase the tolerance of chrysanthemum to freezing stress.

In order to further explore the oxidative damage of chrysantmeum seedlings, we carried out histochemical staining experiments on the leaves. As a whole, chrysanthemum leaves were subjected to more severe oxidative stress under the conditions of freezing than chilling; and under freezing conditions, seedling with prior CA (T03) accumulated less $\mathrm{H}_{2} \mathrm{O}_{2}$ and $\mathrm{O}_{2}{ }^{-}$than seedlings without CA (T04) (Fig. 5b). Furthermore, we determined activities of antioxidant enzymes (POD and CAT) in 
Table 9 Genes encoding cold-related proteins and anti-freezing proteins

\begin{tabular}{|c|c|c|c|c|c|c|c|c|}
\hline & Gene ID & CP1 log2FC & $\mathrm{CP} 1$ regulated & CP2 log2FC & CP2 regulated & CP3 $\log 2 \mathrm{FC}$ & CP3 regulated & Gene description \\
\hline \multirow[t]{3}{*}{$\overline{C O R}$} & c98333.graph_c1 & - & - & 4.07 & up & 4.47 & up & $\begin{array}{l}\text { putative cold-inducible } \\
\text { protein }\end{array}$ \\
\hline & c97739.graph_c0 & 3.41 & up & 4.12 & up & 1.01 & normal & cold-responsive protein \\
\hline & c99607.graph_c0 & 3.15 & up & 1.50 & normal & 3.31 & up & Cold regulated gene 27 \\
\hline \multirow{3}{*}{$\begin{array}{l}\text { Cold shock } \\
\text { proteins }\end{array}$} & c113528.graph_c0 & 2.83 & up & 2.73 & up & 0.01 & normal & Cold shock protein 1 \\
\hline & c94983.graph_c0 & 2.47 & up & 2.52 & up & - & - & Cold shock protein 1 \\
\hline & c99900.graph_c0 & 1.78 & up & 1.19 & normal & 0.37 & normal & $\begin{array}{l}\text { Cold shock domain- } \\
\text { containing protein } 3\end{array}$ \\
\hline \multirow[t]{25}{*}{ AFPs } & c99499.graph_c0 & -1.26 & normal & -2.87 & down & -0.40 & normal & beta-1,3-glucanase \\
\hline & c106137.graph_c0 & 0.85 & normal & 2.24 & up & 1.83 & up & beta-1,3-glucanase \\
\hline & c101035.graph_c0 & -2.55 & down & -3.21 & down & 0.55 & normal & chitinase 2-like \\
\hline & c82667.graph_c0 & 4.46 & up & 8.71 & up & 5.59 & up & Thaumatin-like protein \\
\hline & c82207.graph_c0 & -3.00 & down & -1.66 & normal & -1.40 & normal & Thaumatin-like protein \\
\hline & c107884.graph_c0 & 3.81 & up & 4.24 & up & 2.17 & up & Thaumatin-like protein 1 \\
\hline & c100473.graph_c1 & -2.06 & down & -1.79 & normal & -0.31 & normal & Thaumatin-like protein $1 \mathrm{a}$ \\
\hline & c97008.graph_c0 & -3.44 & down & -2.88 & normal & -1.77 & normal & Thaumatin-like protein 1 \\
\hline & c96509.graph_c0 & 5.01 & up & 4.94 & up & 0.41 & normal & $\begin{array}{l}\text { polygalacturonase- } \\
\text { inhibiting protein } 4\end{array}$ \\
\hline & c92070.graph_c0 & 7.56 & up & 8.54 & up & - & - & $\begin{array}{l}\text { Late embryogenesis } \\
\text { abundant protein }\end{array}$ \\
\hline & c70366.graph_c0 & 5.37 & up & 5.74 & up & 0.05 & normal & $\begin{array}{l}\text { Late embryogenesis } \\
\text { abundant protein }\end{array}$ \\
\hline & c58403.graph_c0 & 4.52 & up & 5.52 & up & 0.24 & normal & $\begin{array}{l}\text { Late embryogenesis } \\
\text { abundant protein }\end{array}$ \\
\hline & c105364.graph_c0 & 1.15 & normal & 7.32 & up & 6.28 & up & $\begin{array}{l}\text { Late embryogenesis } \\
\text { abundant protein }\end{array}$ \\
\hline & c114597.graph_c0 & 0.27 & normal & 1.97 & up & 2.85 & up & $\begin{array}{l}\text { Late embryogenesis } \\
\text { abundant protein }\end{array}$ \\
\hline & c105750.graph_c0 & 2.76 & up & 2.12 & normal & - & - & $\begin{array}{l}\text { Late embryogenesis } \\
\text { abundant protein }\end{array}$ \\
\hline & c100124.graph_c0 & 2.77 & up & 2.27 & up & -0.52 & normal & $\begin{array}{l}\text { Late embryogenesis } \\
\text { abundant protein }\end{array}$ \\
\hline & c110317.graph_c0 & 1.76 & up & 3.51 & up & 2.82 & up & $\begin{array}{l}\text { Late embryogenesis } \\
\text { abundant protein }\end{array}$ \\
\hline & c94818.graph_c0 & - & - & 10.01 & up & 9.79 & up & $\begin{array}{l}\text { Late embryogenesis } \\
\text { abundant protein }\end{array}$ \\
\hline & c78821.graph_c0 & 3.23 & up & 7.04 & up & 6.42 & up & $\begin{array}{l}\text { Late embryogenesis } \\
\text { abundant protein }\end{array}$ \\
\hline & c102635.graph_c0 & 2.79 & up & 1.32 & normal & -0.25 & normal & $\begin{array}{l}\text { Late embryogenesis } \\
\text { abundant protein }\end{array}$ \\
\hline & c108163.graph_c0 & 3.73 & up & 4.59 & up & 2.68 & up & $\begin{array}{l}\text { Late embryogenesis } \\
\text { abundant protein }\end{array}$ \\
\hline & c112429.graph_c0 & 1.99 & up & 3.51 & up & 2.45 & up & $\begin{array}{l}\text { Late embryogenesis } \\
\text { abundant protein }\end{array}$ \\
\hline & c96108.graph_c0 & 1.09 & normal & 6.29 & up & 5.22 & up & $\begin{array}{l}\text { Late embryogenesis } \\
\text { abundant protein }\end{array}$ \\
\hline & c114782.graph_c0 & 0.56 & normal & 1.61 & normal & 2.22 & up & $\begin{array}{l}\text { Late embryogenesis } \\
\text { abundant protein }\end{array}$ \\
\hline & c108048.graph_c2 & 6.00 & up & 6.95 & up & 4.39 & up & $\begin{array}{l}\text { Late embryogenesis } \\
\text { abundant protein }\end{array}$ \\
\hline
\end{tabular}


Table 9 Genes encoding cold-related proteins and anti-freezing proteins (Continued)

\begin{tabular}{|c|c|c|c|c|c|c|c|c|}
\hline & Gene ID & CP1 log2FC & CP1 regulated & CP2 log2FC & $\mathrm{CP} 2$ regulated & CP3 $\log 2 F C$ & CP3 regulated & Gene description \\
\hline \multirow[t]{32}{*}{ HSPS } & c108834.graph_c0 & -0.67 & normal & 4.29 & up & 3.33 & up & Heat shock protein \\
\hline & c100907.graph_c0 & 0.01 & normal & 2.85 & up & 2.48 & up & Heat shock protein \\
\hline & c120647.graph_c0 & - & - & - & - & 3.32 & up & Heat shock protein 70 \\
\hline & c104201.graph_c0 & 1.36 & normal & 2.04 & up & -0.07 & normal & Heat shock $70 \mathrm{kDa}$ protein \\
\hline & c113668.graph_c0 & -1.70 & normal & -2.63 & down & -0.89 & normal & Heat shock 70 kDa protein \\
\hline & c97547.graph_c1 & 4.43 & up & 5.32 & up & 1.26 & up & Heat shock $70 \mathrm{kDa}$ protein \\
\hline & c86961.graph_c0 & -0.15 & normal & 2.23 & up & 1.37 & up & $\begin{array}{l}\text { Heat shock cognate } \\
70 \mathrm{kDa} \text { protein }\end{array}$ \\
\hline & c82373.graph_c0 & - & - & 3.05 & up & - & - & $\begin{array}{l}\text { Heat shock cognate } \\
70 \mathrm{kDa} \text { protein }\end{array}$ \\
\hline & c108184.graph_c0 & 0.93 & normal & 2.56 & up & 1.01 & normal & $\begin{array}{l}\text { Heat shock cognate } \\
70 \mathrm{kDa} \text { protein }\end{array}$ \\
\hline & c107360.graph_c0 & 0.74 & normal & 2.23 & up & 1.51 & up & $\begin{array}{l}\text { Heat shock factor } \\
\text { protein HSF24 }\end{array}$ \\
\hline & c98633.graph_c0 & 0.03 & normal & 1.28 & normal & 1.10 & up & $\begin{array}{l}\text { Heat shock cognate } \\
70 \mathrm{kDa} \text { protein }\end{array}$ \\
\hline & c88835.graph_c0 & -1.57 & normal & 2.03 & up & 1.90 & up & $\begin{array}{l}\text { Heat shock cognate } \\
70 \mathrm{kDa} \text { protein }\end{array}$ \\
\hline & c114383.graph_c0 & 0.88 & normal & 3.24 & up & 2.47 & up & $\begin{array}{l}\text { Heat shock cognate } \\
70 \mathrm{kDa} \text { protein }\end{array}$ \\
\hline & c114642.graph_c0 & 1.03 & normal & 2.34 & up & -0.50 & normal & Heat shock $70 \mathrm{kDa}$ protein \\
\hline & c106065.graph_c0 & 2.03 & up & 2.13 & normal & 0.51 & normal & Heat shock cognate protein \\
\hline & c112665.graph_c0 & 0.39 & normal & 3.17 & up & 1.91 & up & $\begin{array}{l}\text { Heat shock cognate } \\
70 \mathrm{kDa} \text { protein }\end{array}$ \\
\hline & c95742.graph_c0 & 3.89 & up & 3.90 & up & -0.30 & normal & Heat shock $70 \mathrm{kDa}$ protein \\
\hline & c111753.graph_c0 & -0.02 & normal & 2.82 & up & 1.95 & up & $\begin{array}{l}\text { Heat shock cognate } \\
70 \text { kDa protein }\end{array}$ \\
\hline & c81956.graph_c0 & -1.60 & normal & -2.41 & down & -1.84 & down & $\begin{array}{l}\text { Stromal } 70 \mathrm{kDa} \text { heat } \\
\text { shock-related protein }\end{array}$ \\
\hline & c97818.graph_c0 & -2.43 & down & -2.06 & down & -0.93 & normal & $\begin{array}{l}15.4 \mathrm{kDa} \text { class } \vee \text { heat } \\
\text { shock protein }\end{array}$ \\
\hline & c91820.graph_c0 & -1.35 & normal & -2.66 & down & -1.93 & down & $\begin{array}{l}\text { Stromal } 70 \mathrm{kDa} \text { heat } \\
\text { shock-related protein }\end{array}$ \\
\hline & c96991.graph_c0 & -2.12 & down & -2.42 & down & -2.23 & down & $\begin{array}{l}\text { Stromal } 70 \mathrm{kDa} \text { heat } \\
\text { shock-related protein }\end{array}$ \\
\hline & c113713.graph_c1 & -0.33 & normal & -1.35 & normal & 1.65 & up & $\begin{array}{l}22.7 \mathrm{kDa} \text { class IV heat } \\
\text { shock protein }\end{array}$ \\
\hline & c102754.graph_c0 & 3.00 & up & 3.17 & up & 0.01 & normal & $\begin{array}{l}\text { Heat shock cognate } \\
\text { protein } 80\end{array}$ \\
\hline & c112282.graph_c0 & 4.18 & up & 4.97 & up & 1.27 & up & $\begin{array}{l}\text { Heat shock cognate } \\
70 \mathrm{kDa} \text { protein }\end{array}$ \\
\hline & c115107.graph_c2 & 3.11 & up & 3.26 & up & 0.16 & normal & Heat shock protein $90-2$ \\
\hline & c102959.graph_c0 & 3.21 & up & 3.31 & up & -0.06 & normal & Heat shock $70 \mathrm{kDa}$ protein \\
\hline & c112881.graph_c0 & 2.46 & up & 2.55 & up & -0.20 & normal & $\begin{array}{l}\text { Stromal } 70 \mathrm{kDa} \text { heat shock- } \\
\text { related protein }\end{array}$ \\
\hline & c58792.graph_c0 & - & - & 4.51 & up & 3.93 & up & Small heat shock protein \\
\hline & c115107.graph_c0 & 1.87 & up & 1.89 & normal & 0.12 & normal & Heat shock protein 90-2 \\
\hline & c109478.graph_c0 & 0.06 & normal & 2.11 & up & 1.02 & normal & $\begin{array}{l}\text { Heat shock cognate } 70 \mathrm{kDa} \\
\text { protein }\end{array}$ \\
\hline & c99010.graph_c0 & -1.34 & normal & -2.22 & down & -0.64 & normal & 15.7 kDa heat shock protein \\
\hline
\end{tabular}




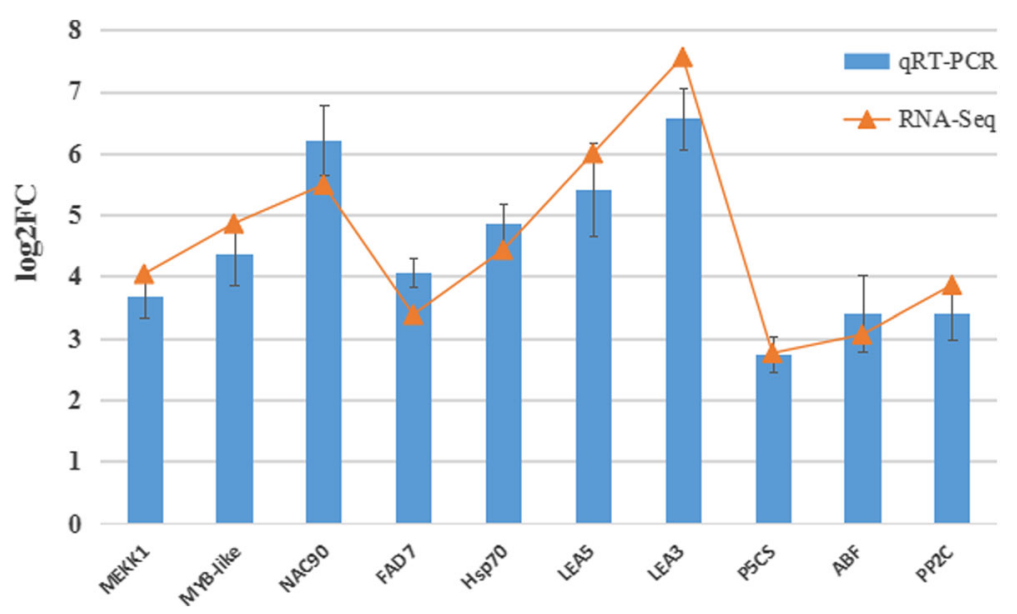

Fig. 4 The relative expression levels of ten DEGs identified in the comparison CP1 between RNA-Seq and qRT-PCR. The genes relative expression levels were determined by $2^{-\Delta \Delta C T}$ as expressed, and were normalized to the expression level of EFTa

chrysanthemum. Under chilling stress, POD activity of seedlings was not significantly different than normal condition, but CAT activity increased obviously. Under freezing conditions, both POD and CAT activities significantly increased, and activities of T03 were remarkably higher than T04 (Fig. 5d, e).

Moreover, we measured the changes in the osmoregulation substances of chrysanthemum at low temperatures. Under chilling stress, both proline and soluble sugar contents of chrysanthemum were increased. And under freezing condition, proline and soluble sugar contents of T03 were substantially increased, whereas T04 was low in proline and soluble sugar contents (Fig. 5f). The result indicated that CA can induce chrysanthemum osmotic regulation systems to work better under freezing conditions.

\section{Discussion}

Low temperature is an important stress factor for plants. It can not only limit the widespread distribution of plants, but also seriously affect the growth and development of them, and cause a series of adverse metabolic reactions [9]. However, 'jinba' exactly is a kind of cutting-chrysanthemum which is difficult to massproduce in winter with normal form. And now, the data available on the molecular basis of chrysanthemum response to cold stress is not limited any longer with the development of high-throughput sequencing.

Based on the quantitative statistics of DEGs in each comparison, we found a lot of genes induced by low temperature and the majority of them involved in upregulation rather than down-regulation (Fig. 2b). From Fig. 2a, we found that some genes may only be induced by freezing and function on protecting chrysanthemum from freezing damage. As expected, more genes were up-regulated in T03 than T04 (Fig. 2b), supporting the statement that CA process may contribute to plants obtaining increased tolerance to freezing conditions [20].

\section{KEGG analysis}

As shown in Table 6, when exposed to chilling conditions, DEGs of chrysanthemum associated with biosynthesis and metabolism pathways were enriched more than freezing conditions, suggesting that chilling stress could induce more biosynthesis and metabolism genes than freezing. However, the pathways of 'Plant-pathogen interaction' and 'Plant hormone signal transduction' were greater enriched in freezing condition than chilling. Plant-pathogen interaction pathway involves lots of sensing and signaling genes related to $\mathrm{Ca}^{2+}$ signal transducion pathway and MAPK cascade, it demonstrated that more genes participated in the signal sensing and transduction pathways were induced by freezing than chilling stress.

In addition, under freezing stress, whether biosynthesis and metabolism related pathways or signal related pathways in CP2 were greater enriched than CP3. It indicated that CA can relieve the inhibition of biosynthesis and metabolism by freezing injury, and strengthen the response of signal transduction pathway to freezing injury.

\section{Low temperature signal transduction}

For surviving in low temperature environment, plants developed a series of complex signaling pathways, and the activities of which are modulated by adding or removing phosphate groups [21]. Lots of protein kinases and protein phosphatases participate in the processes of phosphorylation and de-phosphorylation, such as RLKs, MAPKs, CDPKs, CIPKs, protein phosphatase P (PPP), protein phosphatase $\mathrm{M}$ (PPM), and protein tyrosine phosphatase (PTP) [22]. Larges of previous experiments implicated that RLKs work on hormone signaling events in response to environmental stimuli [23-26]. In our 


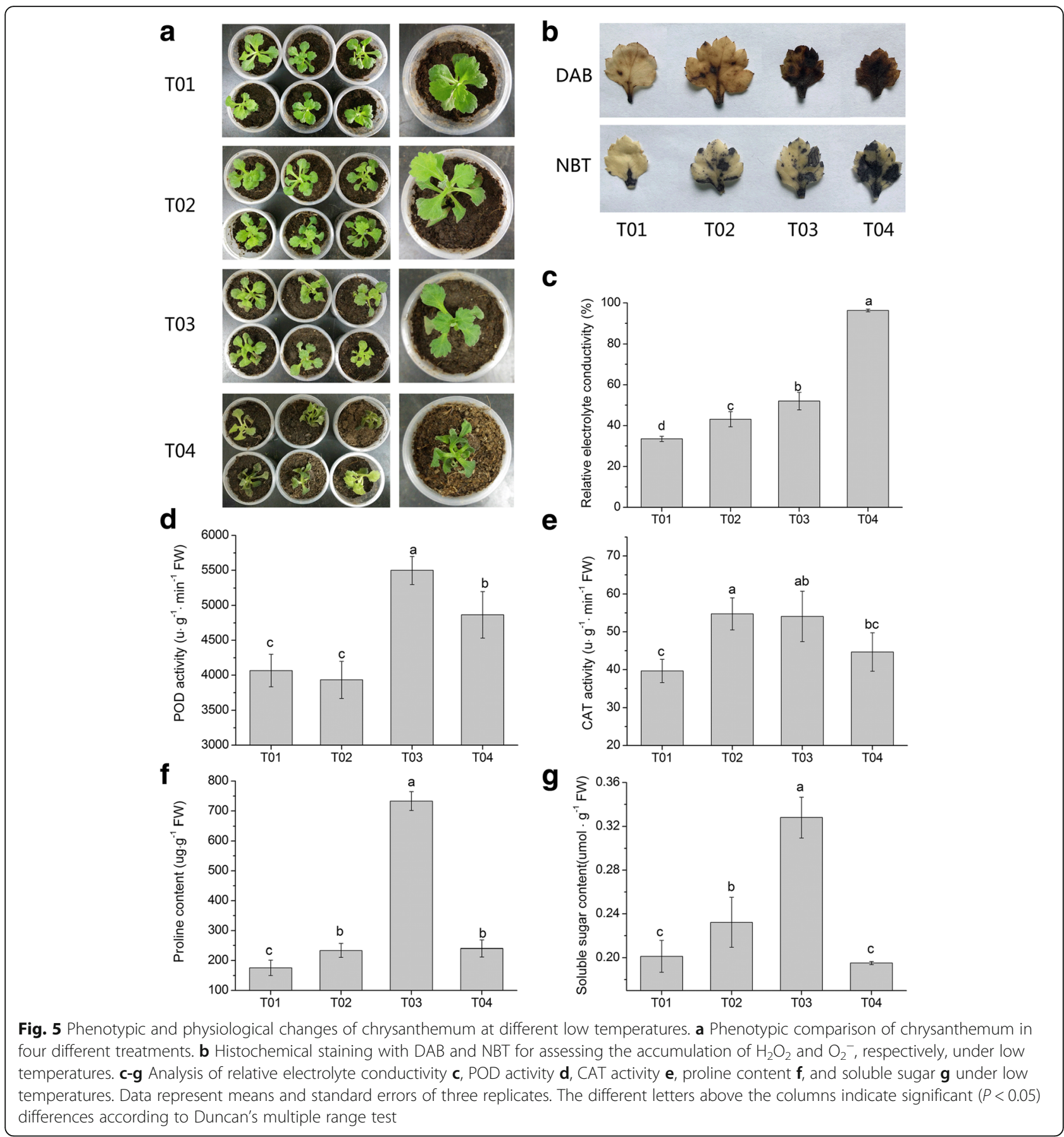

experiment, lots of RLKs were found both in all treatments, and up-regulated RLKs in freezing stress were more than in chilling stress (Additional file 2: Table S1). The MAPK cascade activated by reactive oxygen species mediates cold stress signaling in Arabidopsis [27]. Plants over-expressing $M K K 2$ increased freezing tolerance, whereas $m k k 2$ null mutant plants were hypersensitive to cold stress [27]. Overexpression of OsMAPK5 conferred cold tolerance in rice seedlings [28]. We respectively identified 2, 8, 10 MAPKs genes up-regulated in CP1,
CP2 and CP3, suggesting that MAPK cascade played a significant role in the low temperature stress, especially in freezing stress in chrysanthemum. In addition, protein phosphatase has been shown to be crucial components of MAPKs cascade [21]. Relevantly, several PPP, PPM and PTP differentially expressed in each treatment were identified. CDPKs and CIPKs are two key kinases of the $\mathrm{Ca}^{2+}$-signaling pathway, which is known to be involved in responses to cold stimuli $[29,30]$. And it has been reported that OsCIPKO3, OsCIPK12, OsCDPK7 and 
OsCDPK13 played important roles in conferring cold tolerance in rice [31-33]. In this study, 3, 12, 9 CDPK and 7, 5, 4 CIPK genes were differentially expressed in three treatments, respectively, and all of them were upregulated. These genes may provide excellent genetic resources for breeding engineering of low-temperature tolerance chrysanthemum.

The different expression of genes involving in the signal cascade mechanism can affect the expression of genes participating in the formation of plant hormones such as ABA, ET, SA and JA. And then, theses hormones may amplify the cascades or initiate some new signaling pathways [34]. In this experiment, ABA, ET and JA are top three responsive hormone signal transduction pathways in chrysanthemum, and there were numbers of DEGs involved in them. ABA is a plant hormone extensively involved in environmental stresses. ABA-responsive element (ABRE) and dehydrationresponsive element (DRE) were two cis-acting elements involved in ABA-mediated gene expression [21]. Besides DEGs encoding three key proteins (ABA receptor, PP2C and $\mathrm{SnRK} 2$ ) of ABA signaling pathway were identified, another one $\mathrm{ABF}$ and 11 DRE-binding factors (DREB) were obtained in our study (Additional file 3: Table S2). Both $\mathrm{ABF}$ and DREB can activate the down-stream genes expression in response to cold stress [35]. This indicated that low temperature-induced expression of chrysanthemum appeared to be ABA dependent.

Lipid molecules are also involved in signal transduction during low temperature stress. Phosphatidic acid (one kind of membranous secondary messenger molecule) can be produced by phospholipase D (PLD) [36]. $\mathrm{Li}$ et al. have shown that the cold-induced freezing tolerance of Atpldd T-DNA knock-out mutant Arabidopsis was impaired, whereas that of AtPLDd-overexpression plants was enhanced [37]. In our study, we totally found 6 PLD DEGs, 3, 4 and 2 of which represented upregulation in $\mathrm{CP} 1, \mathrm{CP} 2$ and $\mathrm{CP} 3$, respectively. The upregulation amplitude of PLD genes in CP2 was higher than CP3. This indicated that PLD was closely related to low-temperature tolerance of chrysanthemum, and CA might contribute to improve freezing tolerance of chrysanthemum.

\section{TFs responding to low temperature}

When subjected to low temperature stress, TFs could be activated through a series of signal transduction pathways. Then activated TFs bind specifically to the corresponding cis-acting element to activate the expressions of various downstream resistance-related genes, thereby enhancing the cold tolerance of plants [38]. AP2/ERF, WRKY, MYBrelated, MYB, NAC were five major TF classes identified as DEGs in response to low temperature stress. And some members of above TF families have been identified as regulators involved in low temperature stress responses [39-41]. Among various reported TFs, DREBs/CBFs played pivotal roles in improving low temperature tolerance of plants [34]. Overexpression of Arabidopsis DREBs enhanced chilling or freezing tolerance in many plant species, and overexpression DREB1 of several plant species in transgenic Arabidopsis also conferred tolerance to freezing stress [34]. In our study, a total of 10 DREBs were upregulated under chilling or freezing stress. Interestingly, there were only 3 WRKY and 3 MYB TFs up-regulated in the chilling treatment, whereas respectively about 17 were up-regulated in freezing conditions. It can be inferred that WRKY and MYB TFs may play vital roles in response to the freezing stress. Moreover, some other TF families were also found to be differentially expressed in our study, such as bHLH, bZIP, C2H2, GRAS and C3H. These results suggested that a large number of TFs were involved in the regulation mechanism of chrysanthemum in response to low temperature stress through different pathways.

\section{Cold resistant genes associated with the biofilm system}

When the temperature drops, phase changes firstly occurs in the biofilm membrane lipid, which leads to the increase of membrane permeability and the leakage of electrolyte. Physiologically, Fig. 5c showed the chrysanthemum biofilm system suffered more severe persecution under freezing conditions, especially T04 chrysanthemum. Therefore, we explored the molecular mechanisms of biological membranes. Increasing the proportion of unsaturated fatty acids in membrane lipids is propitious to membrane fluidity, thus decreasing the phase changes temperature of the membrane lipids [42]. Therefore, the content of membrane fatty acid and the fluidity of membrane are closely related to the cold resistance of plants. In molecular terms, we found a total of 12 genes encoding LTPs and 7 genes encoding FADs were differentially expressed from three libraries (CP1, CP2, and CP3). Among them, 7 FADs genes included omega- 6 and omega- 3 fatty acid desaturases genes, which are mainly involved in processes of unsaturated fatty acids (linoleic acid and $\alpha$-linolenic acid) biosynthesis. And previous reports showed that increasing omega-3 desaturase genes expression could enhanced resistance of different plants to cold stress [43, 44]. Meanwhile, PLD and secretory phospholipase A2 (SPLA2) were also two favorable factors of membrane fluidity $[45,46]$. Relevantly, we found numbers of DEGs encoding PLD and SPLA2 in three libraries. These results indicated that chrysanthemum may be able to tolerant low temperatures by enhancing the stabilization of cell membrane. In general, genes encoding LTPs, FADs, PLDs and SPLA2 were obviously much more active in chrysanthemum with CA (T03) than in chrysanthemum without CA (T04) (Table 7) , suggesting that chrysanthemum acquired freezing tolerance from CA process. 
The damage of cell membrane system under low temperature stress may be related to membrane lipid peroxidation induced by free radical and ROS. Membrane lipid peroxidation product malondialdehyde (MDA) conbined with protein can cause membrane protein denaturation, so membrane lipid peroxidation is also an important reason leading to the decrease of membrane lipid fluidity [47]. Fig. 5b showed that chrysanthemum was subjected to more severe reactive oxygen injury under freezing stress than chilling stress, and T04 was more serious than T03. The increase of contents or activities of protective enzymes is beneficial to maintain the balance between ROS production and removal. Under the same freezing condition, activities of POD and CAT enzymes of T03 was higher than that of T04, and more genes encoding peroxidase represented upregulated in T03, suggesting that $\mathrm{CA}$ process induced chrysanthemum to establish a better protective enzyme system to improve their ability to resist frost damage.

In addition, under low temperature stress, the genes encoding antifreeze proteins and molecular chaperones altered to provide protection to plants. LEAs are known for its aggressive response to dehydration; however, its function in freezing tolerance has been confirmed [48]. A total of 16 LEA protein genes among DEGs were identified in our study. Some cold-responsive genes encoded molecular chaperones like HSP70s and HSP90s. A Brassica napus gene $h s p 90$ contributed to freezing tolerance by stabilizing proteins against freeze-induced denaturation [49]. There were 9, 21 and 14 genes encoding HSPs identified in DEGs of CP1, CP2 and CP3, speculating that HSPs chaperones played important roles in resistance to low temperature stresses in chrysanthemum.

\section{Cold resistant genes associated with osmotic regulation system}

Osmotic adjustment is a regulation of plants when dehydration stress evocked by low temperature occurs. As shown in Fig. 5g, low temperature induced the accumulation of soluble sugar in chrysanthemum. Soluble sugar, as an osmotic regulator and an anti dehydrating agent, can reduce cell water potential and enhance water holding capacity [50]. Sugar can provide carbon source and substrate to induce other related cold resistance and physiological and biochemical process, contributing to the enhancement of cold resistance; it also can avoid the protein coagulating caused by the low temperature, to further improve the cold resistance of plant [51, 52]. Significant changes in expressions of the key enzyme genes involved in starch and cellulose degrading, soluble sugars synthesis, and galactose degradation. $\alpha-/ \beta$-amylase and $\beta$-glucosidase were respectively involved in the degradation of starch and cellulose, and the genes encoding these enzymes showed different degrees of rise.
Meanwhile, the genes involved in the processes of sucrose, trehalose and raffinose synthesis were also up regulated, which encoding sucrose-phosphate synthase, sucrose synthase, trehalose phosphate synthase, trehalose phosphatase, galactinol synthase, and raffinose synthase. The previous study reported that overexpression of sucrose-phosphate synthase promoted sucrose levels and increased the degree of cold tolerance in transgenic Arabidopsis [53]. What's more, we found aldose 1epimerase (galM), which acts on the degradation of galactose, and alpha-galactosidase (galA), which hydrolyze substances containing galactoside bonds, were down regulated in T02 or T03. It's beneficial to maintain the stability of soluble sugar content.

Low temperature also induced the accumulation of proline in chrysanthemum (Fig. 5f). When plants are subjected to cold stress, proline can not only reduce cell water potential, but also promote protein hydration, thus playing a certain role in cells protection [54]. P5CS, which participates in the synthesis of proline, was only found to be up-regulated in T02 and T03. PRODH, which participates in the degradation of poline, was only represented up-regulated in T04. It suggests that T03 has a better capacity of maintaining high levels of proline than T04, which is one of reasons why T03 is more resistant to freezing than $\mathrm{T} 04$.

\section{Conclusion}

Our study presents a genome-wide transcript profile of Dendranthema grandiflorum var. jinba, which supported by physiological tests, and provides insights into the molecular mechanisms of D. grandiflorum in response to low temperature. Analyses of physiological and molecular data showed that CA could lead to the establishment of cold resistance mechanism of chrysanthemum, and finally improve the adaptability of chrysanthemum to freezing. And we explored a series of potential chilling-resistant and antifreeze genes associated with low temperature signal transduction, biofilm system and osmotic regulation system, which can serve as candidate genes for coldtolerance molecular breeding project of chrysanthemum.

\section{Additional files}

Additional file 1: Figure S1. Composition of raw reads in the four RNA libraries. Figure S2. Functional classification and pathway assignment of DEGs by KEGG. The $y$-axis indicates the name of the KEGG pathways. The $x$-axis indicates the percentage of the number of annotated DEGs under the pathway in total number of DEGs in all pathways. Figure S3. Transcription factor families occupied proportion in Dendranthema grandiflorum DEGs. (DOC $1620 \mathrm{~kb}$ )

Additional file 2: Table S1. Differentially expressed protein kinases and protein phosphatases genes involved in low temperature responses. (XLS 74 kb) 
Additional file 3: Table S2. Genes involved in ABA signaling pathway and DREBs in response to low temperature. (XLS $27 \mathrm{~kb}$ )

\section{Abbreviations}

ABA: Abscisic acid; ABF: ABA-responsive element binding factor; ABRE: ABAresponsive element; AFPs: Anti-freezing proteins; BP: Biological Processes; BR: Brassinosteroid; CA: Cold acclimation; CAT: Catalase; CC: Cell Component; CDPK: Calcium-dependent protein kinase; CIPK: CBL-interacting protein kinase; CK: Cytokinin; COG: Cluster of orthologous groups; COR: Coldregulated gene; DEGs: Differentially expressed genes; DRE: Dehydrationresponsive element; DREB: DRE-binding factors; EC: Electrolyte conductivity; eggNOG: Evolutionary genealogy of genes: Non-supervised Orthologous Groups; ET: Ethylelne; FADs: Fatty acid desaturase; FPKM: Fragments per kilobase of transcript per million fragments mapped; GA: Gibberellin; galA: Alpha-galactosidase; galM: Aldose 1-epimerase; GLPs: Beta-1,3 glucanase proteins; GO: Gene Ontology; HSPs: Heat shock proteins; JA: Jasmonic acid; KEGG: Kyoto Encyclopedia of Genes and Genomes; KOG: euKaryotic Orthologous Groups; LEAs: Late-embryogenesis-abundant proteins; LTPS: Lipid-transfer proteins; MAPK: Mitogen-activated protein kinase; MDA: Malondialdehyde; MF: Molecular Function; NGS: Nextgeneration sequencing; Nr: NCBI non-redundant; P5CS: Pyrroline-5carboxylate synthetase; Pfam: Protein family; PGIPs: Polygalacturonaseinhibiting proteins; PK: Protein kinase; PLD: Phospholipase D; POD: Peroxidase; PP: Protein phosphatase; PP2C: Protein phosphatase 2C; PPM: Protein phosphatase M; PPP: Protein phosphatase P; PTP: Protein tyrosine phosphatase; qRT-PCR: Quantitative real-time polymerase chain reaction; RLKs: Receptor-like kinases; ROS: Reactive oxygen species; RSEM: RNASeq by Expectation Maximization; SA: Salicylic acid; SnRK2: Serine/threonineprotein kinase; SPLA2: Phospholipase A2; SPS: Sucrose-phosphate synthase; TFs: Transcription factors; TLPs: Thaumatin-like proteins; TPP: Trehalose phosphatase; TPS: Trehalose phosphate synthase

\section{Funding}

The RNAseq analysis was supported by National Natural Science Foundation of China (31770742). The funding body had no role in the design of the study, the interpretation of data and in writing the manuscript.

\section{Availability of data and materials}

The raw sequencing data have been submitted to the NCBI Sequence Read Archive database with accession number GSE102413.

\section{Authors' contributions}

KW and QLL conceived and designed the experiments. KW, ZB, BJ, FZ and QYL performed the experiments. KW, QLL, YP, LZ, YJ and GL analyzed and interpreted the sequence data. KW wrote the manuscript. All authors read and approved the final manuscript.

\section{Ethics approval and consent to participate}

Chrysanthemum materials of this study were provided by plant tissue culture room of Sichuan Agricultural Uniersity. No field permission was necessary to collect the plant samples in this study. This experimental research on chrysanthemum complied with institutional, national, or international guidelines.

\section{Competing interests}

The authors declare that the research was conducted in the absence of any commercial or financial relationships that could be construed as a potential conflict of interest.

\section{Publisher's Note}

Springer Nature remains neutral with regard to jurisdictional claims in published maps and institutional affiliations.

\section{Received: 10 August 2017 Accepted: 22 April 2018}

\section{Published online: 02 May 2018}

\section{References}

1. Han J, Thamilarasan SK, Natarajan S, Park JI, Chung MY, Nou IS. De novo assembly and transcriptome analysis of bulb onion (Allium cepa L.) during cold acclimation using contrasting genotypes. PLoS One. 2016;11:e0161987.
2. Zhu J, Dong CH, Zhu JK. Interplay between cold-responsive gene regulation, metabolism and RNA processing during plant cold acclimation. Curr Opin Plant Biol. 2007;10:290-5.

3. Chinnusamy V, Zhu J, Zhu JK. Cold stress regulation of gene expression in plants. Trends Plant Sci. 2007;12:444-51.

4. Qu Y, Zhou A, Zhang $X$, Tang H, Liang M, Han $H$, et al. De novo transcriptome sequencing of low temperature-treated phlox subulata and analysis of the genes involved in cold stress. Int J Mol Sci. 2015;16:9732-48.

5. Moliterni VMC, Paris R, Onofri C, Orrù L, Cattivelli L, Pacifico D, et al. Early transcriptional changes in Beta vulgaris in response to low temperature. Planta. 2015;242:187-201.

6. Nah G, Lee M, Kim DS, Rayburn AL, Voigt T, Lee DK. Transcriptome analysis of spartina pectinata in response to freezing stress. PLoS One. 2016;11:e0152294

7. Wang XC, Zhao QY, Ma CL, Zhang ZH, Cao HL, Kong YM, et al. Global transcripome profiles of Camellia sinensis during cold acclimation. BMC Genomics. 2013;14:415.

8. Wang J, Yang Y, Liu X, Huang J, Wang Q. Gu J, et al. transcriptome profiling of the cold response and signaling pathways in Lilium lancifolium. BMC Genomics. 2014;15:203.

9. Li Q, Lei S, Du K, Li L, Pang X, Wang Z, et al. RNA-seq based transcriptomic analysis uncovers a-linolenic acid and jasmonic acid biosynthesis pathways respond to cold acclimation in Camellia japonica. Sci Rep. 2016;6:36463.

10. Grabherr MG, Haas BJ, Yassour M, Levin JZ, Thompson DA, Amit I, et al. Full-length transcriptome assembly from RNA-Seq data without a reference genome. Nat Biotechnol. 2011;29:644-52.

11. Altschul SF, Madden TL, Schäffer AA, Zhang J, Zhang Z, Miller W, et al. Gapped BLAST and PSI BLAST: a new generation of protein database search programs. Nucleic Acids Res. 1997;25:3389-402.

12. Xie C, Mao X, Huang J, Ding Y, Wu J, Dong S, et al. KOBAS 2.0: a web server for annotation and identification of enriched pathways and diseases. Nucleic Acids Res. 2011;39:W316-22.

13. Eddy SR. Profile hidden Markov models. Bioinformatics Italic. 1998;14:755-63.

14. Wang K, Zhong M, Wu YH, Bai ZY, Liang QY, Liu QL, et al. Overexpression of a chrysanthemum transcription factor gene DgNAC1 improves the salinity tolerance in chrysanthemum. Plant Cell Rep. 2017;36:571-81.

15. Ranieri A, Petacco F, Castagna A, Soldatini GF. Redox state and peroxidase system in sunflower plants exposed to ozone. Plant Sci. 2000;159:159-67.

16. Zhang L, Xi D, Luo L, Meng F, Li Y, Wu CA, et al. Cotton GhMPK2 is involved in multiple signaling pathways and mediates defense responses to pathogen infection and oxidative stress. FEBS J. 2011;278:1367-78.

17. Irigoyen JJ, Emerich DW, Sanchez-Diaz M. Water stress induced changes in concentrations of proline and total soluble sugars in nodulated alfalfa (Medicago sativa) plants. Physiol Plant. 1992;84:55-60.

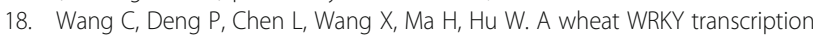
factor TaWRKY10 confers tolerance to multiple abiotic stresses in transgenic tobacco. PLoS One. 2013;8:e65120.

19. Li B, Takahashi D, Kawamura Y, Uemura M. Comparison of plasma membrane proteomic changes of Arabidopsis suspension-cultured cells (T87 line) after cold and ABA treatment in association with freezing tolerance development. Plant Cell Physiol. 2012;53:543-54.

20. Chen L, Fan J, Hu L, Hu Z, Xie Y, Zhang Y, et al. A transcriptomic analysis of bermudagrass (Cynodon dactylon) provides novel insights into the basis of low temperature tolerance. BMC Plant Biol. 2015;15:216.

21. Pareek A, Sopory SK, Bohnert HJ. Govindjee. Abiotic stress adaptation in plants: physiological, molecular and genomic foundation. Berlin: Springer; 2010.

22. Denu JM, Stuckey JA, Saper MA, Dixon JE. Form and function in protein dephosphorylation. Cell. 1996;87:361-4.

23. Johnson KL, Ingram GC. Sending the right signals: regulating receptor kinase activity. Curr Opin Plant Biol. 2005;8:648-56.

24. Morris ER, Walker JC. Receptor-like protein kinase: the keys to response. Curr Opin Plant Biol. 2003;6:339-42.

25. Tichtinsky G, Vanoosthuyse V, Cock JM, Gaude T. Making inroads into plant receptor kinase signaling pathways. Trends Plant Sci. 2003;8:231-7.

26. Haubrick LL, Assmann SM. Brassinosteroids and plant function: some clues, more puzzles. Plant Cell Environ. 2006;29:446-57

27. Teige M, Scheikl E, Eulgem T, Doczi R, Ichimura K, Shinozaki K, et al. The MKK2 pathway mediates cold and salt stress signaling in Arabidopsis. Mol Cell. 2004;15:141-52.

28. Xiong $L$, Yang $Y$. Disease resistance and abiotic stress tolerance in rice are inversely modulated by an abscisic acid-inducible mitogen-activated protein kinase. Plant Cell. 2003;15:745-59. 
29. Cheong YH, Kim KN, Pandey GK, Gupta R, Grant JJ, Luan S. CBL1, a calcium sensor that differentially regulates salt, drought and cold responses in Arabidopsis. Plant Cell. 2003;15:1833-45.

30. Kim KN, Cheong YH, Grant JJ, Pandey GK, Luan S. CIPK3, a calcium sensorassociated protein kinase that regulates abscisic acid and cold signal transduction in Arabidopsis. Plant Cell. 2003;15:411-23.

31. Saijo Y, Hata S, Kyozuka J, Shimamoto K, Izui K. Overexpression of a single $\mathrm{Ca}^{2+}$-dependent protein kinase confers both cold and salt/drought tolerance on rice plants. Plant J. 2000;23:319-27.

32. Saijo Y, Kinoshita N, Ishiyama K, Hata S, Kyozuka J, Hayakawa T, et al. A Ca ${ }^{2}$ ${ }^{+}$-dependent protein kinase that endows rice plants with cold- and saltstress tolerance functions in vascular bundles. Plant Cell Physiol. 2001;42: 1228-33.

33. Xiang $Y$, Huang $Y$, Xiong L. Characterization of stressresponsive CIPK genes in rice for stress tolerance improvement. Plant Physiol. 2007:144:1416-28.

34. Yadav SK. Cold stress tolerance mechanisms in plants. A review. Agron Sustain Dev. 2010;30:515-27.

35. Thomashow MF. Arabidopsis thaliana as a model for studying mechanisms of plant cold tolerance. Cold Spring Harbor Monograph Archive. 1994;27: 807-34.

36. Meijer HJ, Munnik T. Phospholipid-based signaling in plants. Annu Rev Plant Biol. 2003:54:265-306.

37. Li W, Li M, Zhang W, Welti R, Wang X. The plasma membrane-bound phospholipase Ddelta enhances freezing tolerance in Arabidopsis thaliana. Nat Biotechnol. 2004;22:427-33.

38. Kasuga M, Liu Q, Miura S, Yamaguchishinozaki K, Shinozaki K. Improving plant drought, salt, and freezing tolerance by gene transfer of a single stress-inducible transcription factor. Novartis Found Symp. 1999;17:287.

39. Hu H, You J, Fang Y, Zhu X, Qi Z, Xiong L. Characterization of transcription factor gene SNAC2 conferring cold and salt tolerance in rice. Plant Mol Biol. 2008;67:169-81.

40. Ito Y. Functional analysis of rice DREB1/CBF-type transcription factors involved in cold-responsive gene expression in transgenic rice. Plant Cell Physiol. 2006;47:141-53.

41. Vannini C, Locatelli F, Bracale M, Magnani E, Marsoni M, Osnato M, et al. Overexpression of the rice Osmyb4 gene increases chilling and freezing tolerance of Arabidopsis thaliana plants. Plant J. 2004:37:115-27.

42. Zhou Z, Wang MJ, Zhao ST, Hu JJ, Lu MZ. Changes in freezing tolerance in hybrid poplar caused by up- and down-regulation of PtFAD2 gene expression. Transgenic Res. 2010;19:647-54.

43. Domínguez T, Hernández ML, Pennycooke JC, Jiménez P, Martínez-Rivas JM, Sanz C, et al. Increasing $\omega-3$ desaturase expression in tomato results in altered aroma profile and enhanced resistance to cold stress. Plant Physiol. 2010;153:655-65.

44. Kodama H, Hamada T, Horiguchi G, Nishimura M, Iba K. Genetic enhancement of cold tolerance by expression of a gene for chloroplast [omega]-3 fatty acid desaturase in transgenic tobacco. Plant Physiol. 1994;105:601-5.

45. Gardiner J, Marc J. Phospholipases may play multiple roles in anisotropic plant cell growth. Protoplasma. 2013;250:391-5.

46. Yang X, Sheng W, He Y, Cui J, Haidekker MA, Sun GY, et al. Secretory phospholipase A2 type III enhances alpha-secretase-dependent amyloid precursor protein processing through alterations in membrane fluidity. J Lipid Res. 2010;51:957-66.

47. Peng XN, Yi ZL, Jiang JX. Progress in the study of cold resistance in plant. Biotechnol Bull. 2007:4:15-8. https://doi.org/10.3969/.issn.1002-5464.2007.04.004.

48. Sasaki K, Christov NK, Tsuda S, Imai R. Identification of a novel LEA protein involved in freezing tolerance in wheat. Plant Cell Physiol. 2014;55:136-47.

49. Krishna P, Sacco M, Cherutti JF, Hill S. Cold-induced accumulation of hsp 90 transcripts in Brasscia napus. Plant Physiol. 1995;107:915-23.

50. Ma YY, Xiao X, Zhang WN. Research progress of plants under cold stress. J. Anhui. Agric Sci. 2012;40:7007-8.

51. Liu WY, Liu JX, Han B, Zhang R. Determination of reduced sugar content in potatoes. Agriculture \& Technology. 2013;1(26):33.

52. Xu CX. Research progress on the mechanism of improving plant cold hardiness. Acta Ecol Sin. 2012;32:7966-80. https://doi.org/10.5846/ stxb201106260945

53. Liu WY. Plant stress and genes. Bei Jing: Beijing Institute of Technology Press; 2015

54. Liu HM, Wen YH, Wang SK, You Y. A review of plant cold resistance. Northern Horticulture. 2003;6:14-5.

\section{Ready to submit your research? Choose BMC and benefit from:}

- fast, convenient online submission

- thorough peer review by experienced researchers in your field

- rapid publication on acceptance

- support for research data, including large and complex data types

- gold Open Access which fosters wider collaboration and increased citations

- maximum visibility for your research: over $100 \mathrm{M}$ website views per year

At BMC, research is always in progress.

Learn more biomedcentral.com/submissions 